Charlotte Christiansen

Decomposing European Bond and Equity Volatility

Finance

Research Group

Department of Accounting,

Finance and Logistics 


\title{
Decomposing European Bond and Equity Volatility ${ }^{1}$
}

\author{
Charlotte Christiansen ${ }^{2}$ \\ Aarhus School of Business
}

June 30, 2004

\begin{abstract}
${ }^{1}$ The author gratefully acknowledges constructive comments and suggestions from the seminar participants at the Department of Finance at Copenhagen Business School (April 2004), the Aarhus Econometrics meeting on Svinkløv Badehotel (May 2004), and the Finance/Econometrics Workshop at University of Aarhus (May 2004).

${ }^{2}$ Charlotte Christiansen, Aarhus School of Business, Fuglesangs Alle 4, 8210 Aarhus V, Denmark. Phone: +45 8948 6691, email: mail@CharlotteChristiansen.dk, URL: www.CharlotteChristiansen.dk.
\end{abstract}




\title{
Decomposing European Bond and Equity Volatility
}

\begin{abstract}
The paper investigates volatility spillover from US and aggregate European asset markets into European national asset markets. A main contribution is that bond and equity volatilities are analyzed simultaneously. A new model belonging to the "volatilityspillover" family is suggested: The conditional variance of e.g. the unexpected German stock return is divided into separate effects from the contemporaneous idiosyncratic variance of US bonds, US stocks, European bonds, European stocks, German bonds, and German stocks. Significant volatility-spillover effects are found. The national bond (stock) volatilities are mainly influenced by bond (stock) effects. Global, regional, and local volatility effects are all important. The introduction of the euro is associated with a structural break.
\end{abstract}

Keywords: European Asset Markets; GARCH; International Finance; Volatility Spillover JEL Classifications: C32; G12; G15 


\section{Introduction}

This paper contains an analysis of factors affecting the variances of national European bond returns as well as the variances of national European stock returns. We apply the so-called volatility-spillover framework. The variance of the unexpected return of e.g. the German bond market is divided into a part caused by idiosyncratic US (global) bond effects, US stock effects, European (regional) bond effects, European stock effects, and pure German (local) bond effects. Equivalently, the variance of the unexpected German stock return is divided into the same five effects in addition to pure German stock effects. Bond and stock markets are investigated simultaneously, which - we believe - is new to the volatility-spillover literature. Moreover, to the best of our knowledge, we contribute methodologically to the literature by generalizing the volatility-spillover model.

The empirical analysis brings some light on the integration of the European financial markets. Local effects should be weaker, the more integrated the European financial markets are. Financial integration appears to be a major concern of the policy makers in the European Union (EU) as the EU has launched several policy initiatives to obtain financial integration, cf. Hartmann, Maddaloni and Manganelli (2003). Presumably, the introduction of the euro has worked in favor of financial integration. The observed home bias in Europe has decreased in the previous years, cf. e.g. Baele, Ferrando, Hördahl, Krylova and Monnet (2004). This might indicate that the European financial markets have become more integrated. When the importance of country specific effects are low, the potential benefits of diversification are also small. It is believed that stock and bond volatilities are linked via information spillover, cf Fleming, Kirby and Ostdiek (1998) for a model and analysis of US stock, bond, and money markets. Fleischer (2004) extends this model to also include the equivalent Australian markets. Here we investigate the European bond and stock market volatility linkages. Finally, we examine how important global and regional effects are for the European bond and equity volatility.

We provide a new volatility-spillover model that covers both bond and stock markets simultaneously. Our model is derived from Bekaert and Harvey 
(1997), Ng (2000), Bekaert, Harvey and Ng (forthcoming), and Baele (forthcoming). Ng (2000) and Bekaert et al. (forthcoming) divide the conditional variance of the unexpected stock return for country $i$ into three effects; global effects, regional effects, and own market effects. The literature applies multistep estimation procedures, e.g. $\mathrm{Ng}$ (2000) applies two (and a half) steps: The first step specifies an ordinary bivariate GARCH model for the US and Japanese stock returns. As an intermediate step, the residuals from the first step are orthogonalized. In the last step, the US and Japanese orthogonalized residuals are applied as additional explanatory variables in univariate models for the national stock returns. The orthogonalized residuals provide the volatility spillover in that they make the variance of the unexpected return of the individual stock market a linear function of contemporaneous US idiosyncratic variance, Japanese idiosyncratic variance, and own market idiosyncratic variance. We also apply a multiple-step estimation procedure: In the first step, a multivariate (dynamic conditional correlation) DCC-GARCH model for the US bond return, the US stock return, the European bond return, and the European stock return is estimated. In the second step, the residuals are orthogonalized. In the third step, the orthogonalized residuals are applied as additional explanatory variables in a univariate model for country $i$ 's bond return, hereby providing volatility-spillover from the US bond, US stock, European bond, and European stock markets into the individual bond markets. In the fourth step, the orthogonalized residuals from the second step as well as the own bond residual from the third step are applied as explanatory variables in univariate models for the return on country $i$ 's stock market. Thus, there is also volatility spillover from own bonds. The volatility-spillover effects are allowed to change (independently of each other) after the launch of the euro in the beginning of 1999. The model allows us to divide the conditional variance of the unexpected return of bonds (stocks) into separate proportions caused by the five (six) different effects mentioned above. To the best of our knowledge, we add to the literature model-wise; our model allows volatility spillover from four global/regional markets instead of just two as in previous models and we also allow the own bond market to influence own stock market.

We investigate nine European Union member countries' bond and stock 
markets. We apply weekly data that cover the period from 1988 to 2003 . We find that the conditional bond-stock correlations have gone from positive to negative in the last part of the sample. Before the euro, there is significant volatility-spillover to the individual bond markets from US bonds, US stocks, and European bonds and after the euro only from the US bonds and European bonds. Before the euro, the main part of the conditional variances of the unexpected return on the bond markets are caused by aggregate European bond effects and own bond market effects. US bond market effects and US stock market effects are also fairly large. After the euro, the European bond market effects are strongest followed by US bond market effects. Own bond market effects have decreased dramatically. Before the euro, there is significant volatility spillover to the stock markets from US bonds, US stocks, European bonds, and own bonds and after the euro only from US stocks and European stocks. Before the euro, the own stock market effects and US stock market effects are the most important for the conditional variance of the unexpected return of the stock market. The European stock effects and the US bond effects are small. After the euro, own stock market effects, US stock market effects, and European stock market effects are all strong. The results are to some extend influenced by the ordering of the variables in the orthogonalization. Our results indicate that bond (stock) market volatility is mainly influenced by bond (stock) market effects. This might suggest to analyze bond (stock) market variability separately from stock (bond) market variability. After the introduction of the euro, the local bond market effects have become smaller, whereas the local stock market effects are still sizeable. There appears to be room for further integration in the European financial markets, especially for the equity markets. Both global and regional effects are important for European bond and stock variances.

The previous analysis of volatility linkages between financial markets have mainly concentrated on international stock markets and to a lesser extend on foreign exchange markets, whereas bond markets have almost been crowded out. The volatility-spillover literature was introduced by Engle, Ito and Lin (1990). They find significant volatility-spillover effects at play at the foreign exchange market. Lin, Engle and Ito (1994) find significant volatilityspillover effects between the US and Japanese equity markets. Bekaert and 
Harvey (1997), Ng (2000), and Baele (forthcoming) find significant volatilityspillover effects into national stock markets. Bekaert and Harvey (1997) investigate how global volatility-spillover effects influence emerging stock market volatility. $\mathrm{Ng}$ (2000) breaks the variance of various pacific basin stock markets into global effects (US), regional effects (Japanese), and local effects. Baele (forthcoming) investigates how US and aggregate European volatility spills over into various European stock markets. Christiansen (2003) finds significant volatility spillover from US and European bond markets into national European bond markets.

There is not a large body of literature that deals with the interdependencies between stock and bond markets. Campbell and Ammer (1993) find that the correlation between US bonds and stocks is low because changes in expected future inflation affect bonds and stocks with opposite signs. This offsets the strong positive correlation stemming from the real interest rate and expected excess returns. Yet, the volatility linkages between the US stock and bond markets are strong, cf. Fleming et al. (1998). ${ }^{1}$ Fleischer (2004) also finds strong volatility linkages between US and Australian bond and stock markets. Fama and French (1993) find that the links between US stock and bond markets are mainly caused by term-structure factors. Connolly, Stivers and Sun (forthcoming; 2004) use implied volatility indices (that measure stock market uncertainty) to explain the time variation in the correlation between stocks and bonds in the US and in various European countries. They find a negative relation between current implied equity volatility and the future correlation between US stocks and bonds. Cappiello, Engle and Sheppard (2003) apply the dynamic conditional correlation model of Engle (2002) to investigate international bond and equity markets. For Europe, the conditional correlations have increased after the introduction of the euro, and the introduction of the euro appears to indicate a structural break. Hartmann et al. (2003) find that the European financial markets have become more integrated after the introduction of the euro, but they are still not fully integrated. Ilmanen (2003) investigates the correlation between US stocks and bonds (using rolling window correlation coefficients) and finds

\footnotetext{
${ }^{1}$ In contrast, Antell (2004) using a similar framework as Fleming et al. (1998) finds weak volatility linkages between Finnish stock and bond markets.
} 
that it has turned from positive to negative since 1998. The correlation between stocks and bonds tends to be positive in the long run because they share discount rate uncertainty. In periods of "flight-to-quality" bonds and stocks are negatively correlated. Ilmanen (2003) conjectures that the change in sign of the correlation is caused by change in the direction of causality; the causality from bonds to stocks is positive and it is negative the opposite way.

The remaining part of the paper is structured as follows. In the next section the volatility-spillover model is described. Subsequently, the data are presented in Section 3 whereafter the empirical findings are discussed in Section 4. Finally, section 5 concludes.

\section{The Volatility-Spillover Model}

In this section we describe a new volatility-spillover model. It is fairly simple in that each of the volatility-spillover parameters is assumed to take on a constant value before the launch of the euro and another constant value after the euro. Notwithstanding this, the model offers a substantial generalization of the existing volatility-spillover models.

For each country $(i=1,2, \ldots, 9)$ there are six return series of interest.

- $R_{1 t}$ : US bond return

- $R_{2 t}$ : US stock return

- $R_{3 t}$ : European bond return

- $R_{4 t}$ : European stock return

- $R_{i 5 t}$ : Country $i$ 's bond return

- $R_{i 6 t}$ : Country $i$ 's stock return

Below we omit $i$ from the subscript when convenient. The first four return series are seen to be identical for the analysis of all countries. The model is estimated stepwise and we organize the presentation around these steps. The first two steps are identical for all countries and concern the returns of 
the US and European bond and stock markets, $R_{1 t}, \ldots, R_{4 t}$. In contrast, the last two steps are estimated separately for each country. The third step concerns the return on country $i$ 's bond market, $R_{i 5 t}$, and the fourth step concerns the return on country $i$ 's stock market, $R_{i 6 t}$.

Our model extends the volatility-spillover models applied in the previous literature. In particular, it builds on the stock market volatility-spillover model of $\mathrm{Ng}$ (2000): That model makes use of the stock market series $R_{2 t}, R_{4 t}$, and $R_{i 6 t}$. The first step of the estimation is similar to our first step, except that it is conducted with just two series $R_{2 t}$ and $R_{4 t}$ and therefore a bivariate model is estimated. The residuals are then orthogonalized. The last step is similar to our fourth step, except that it applies only two orthogonalized residuals as additional explanatory variables to explain the individual stock returns $\left(R_{i 6 t}\right)$.

\subsection{Step 1: US and European Returns}

First, we specify a multivariate model for the return of the US and European bond and stock indices, i.e. for $R_{t}=\left\{R_{j t}\right\}$ where $j=1, \ldots, 4$. To account for possible serial correlation, the conditional mean evolves according to a $\operatorname{VAR}(1)$ process.

$$
R_{t}=\Phi_{0}+\Phi_{1} R_{t-1}+\epsilon_{t}
$$

$\Phi_{0}$ and $\Phi_{1}$ are a $4 \times 1$ vector and a $4 \times 4$ matrix of constants, respectively. The residuals, $\epsilon_{t}$, have mean zero and conditional covariance matrix $H_{t}$.

$\epsilon_{t}$ follows a multivariate GARCH model, possibly including asymmetry. To account for the recent changes in the sign of the correlation between stock and bond returns, we apply a model with time-varying conditional correlation cf. the discussion of Ilmanen (2003) in the introduction. In particular, we apply the dynamic conditional correlation (DCC) model of Engle (2002) and Tse and Tsui (2002) as specified in the latter reference. The DCC model extends the constant conditional correlation (CCCOR) model of Bollerslev (1990) as well as the asymmetric CCCOR of Kroner and Ng (1998) while preserving their simplicity. ${ }^{2}$ The differences between the two DCC specifications are laid out in Bauwens, Laurent and Rombouts (2003). The main

\footnotetext{
${ }^{2}$ As an example, there are 42 parameters in the symmetric 4-dimensional BEKK model
} 
advantage of the Tse and Tsui (2002) version of DCC is that they - unlike Engle (2002) - explicitly model the time series evolution of the conditional correlation matrix. The main force of the Engle (2002) version of the DCC is that the conditional variance equations and conditional correlation equations can be estimated in two separate steps.

The conditional covariance matrix is given as:

$$
H_{t}=D_{t} \Gamma_{t} D_{t}
$$

where $D_{t}$ is a diagonal matrix with the square roots of the conditional variances in the diagonal:

$$
D_{t}=\left(\begin{array}{cccc}
\sqrt{h_{1 t}} & & & 0 \\
& \sqrt{h_{2 t}} & & \\
& & \sqrt{h_{3 t}} & \\
0 & & & \sqrt{h_{4 t}}
\end{array}\right)
$$

$\Gamma_{t}$ is the time-varying conditional correlation matrix. The conditional correlation matrix evolves according to an autoregressive process resembling the GARCH(1,1) process:

$$
\Gamma_{t}=\left(1-\theta_{1}-\theta_{2}\right) \Gamma+\theta_{1} \Gamma_{t-1}+\theta_{2} \Psi_{t-1}
$$

where $\Gamma$ is a positive definite $4 \times 4$ matrix of constants with unit diagonal elements. $\Psi_{t-1}$ is the sample correlation matrix of the standardized residuals lagged $1,2,3$, and 4 periods. The values of $\theta_{1}$ and $\theta_{2}$ are restricted equivalently to the parameters in the $\operatorname{GARCH}(1,1)$ model: $\theta_{1}, \theta_{2} \geq 0$ and $\theta_{1}+\theta_{2} \leq 1$. In the CCCOR model the correlation matrix is constant: $\Gamma_{t}=\Gamma \forall t$ (i.e. $\left.\theta_{1}=\theta_{2}=0\right)$. Thus, the CCCOR model is a testable restriction in the DCC model.

The conditional variances evolve according to the asymmetric GJR-GARCH( $(1,1)$ specification, cf. Glosten, Jagannathan and Runkle (1993);

$$
h_{j t}=\omega_{j}+\alpha_{j} \epsilon_{j, t-1}^{2}+\beta_{j} h_{j, t-1}+\alpha_{j}^{*} \epsilon_{j, t-1}^{2} I_{j, t-1} \text { for } j=1, \ldots, 4
$$

compared to 18 in the corresponding CCCOR model and 20 in the corresponding DCC model. 
where $I_{j, t-1}=1$ when $\epsilon_{j, t-1}<0$, and $\omega_{j}>0, \alpha_{j}, \beta_{j}, \alpha_{j}+\frac{1}{2} \alpha_{j}^{*} \geq 0$, and $\alpha_{j}+\beta_{j}+\frac{1}{2} \alpha_{j}^{*} \leq 1$. If $\alpha_{i}^{*}$ is positive it means that negative shocks have more effect than positive shocks, which is the prevailing hypothesis (for equity markets).

We use the (modified) residuals as input in later steps.

\subsection{Step 2: Orthogonalization}

In an intermediate step, we orthogonalize the residuals from the previous step using a Cholesky decomposition. The orthogonalized residuals are denoted the idiosyncratic shocks, $e_{t}$. The orthogonalization is conducted in the following order; US bonds, US stocks, European bonds, and European stocks. $^{3}$ "Geographically", this is equivalent to $\mathrm{Ng}$ (2000) who puts US (global) stock effects first followed by Japanese (regional) stock effects. Subsequently, we let bonds influence stocks. However, this is not as self evident as "global $\rightarrow$ regional $\rightarrow$ local". On the one hand, e.g. the present value model would suggest that the influence goes from bond markets to stock markets. On the other hand, in periods of "flight-to-quality" the influence goes the opposite direction. This might indicate that the ordinary situation is "bond $\rightarrow$ stock" which we therefore concentrate on.

At the two extremes the order of orthogonalization implies that the US bond residuals only depend on own idiosyncratic shocks, and the European stock residuals depend on all four idiosyncratic shocks. The relation between the residuals (LHS) and the idiosyncratic shocks (RHS) is shown below:

$$
\begin{aligned}
\epsilon_{1 t} & =e_{1 t} \\
\epsilon_{2 t} & =k_{1, t-1} e_{1 t}+e_{2 t} \\
\epsilon_{3 t} & =k_{2, t-1} e_{1 t}+k_{3, t-1} e_{2 t}+e_{3 t} \\
\epsilon_{4 t} & =k_{4, t-1} e_{1 t}+k_{5, t-1} e_{2 t}+k_{6, t-1} e_{3 t}+e_{4 t}
\end{aligned}
$$

\footnotetext{
${ }^{3}$ We cary out robustness checks for the order of orthogonalization.
} 
This is conveniently restated using matrix notation

$$
\epsilon_{t}=\left(\begin{array}{cccc}
1 & 0 & 0 & 0 \\
k_{1, t-1} & 1 & 0 & 0 \\
k_{2, t-1} & k_{3, t-1} & 1 & 0 \\
k_{4, t-1} & k_{5, t-1} & k_{6, t-1} & 1
\end{array}\right) e_{t}=K_{t-1} e_{t}
$$

The conditional covariance matrix of the idiosyncratic shocks is denoted $\Sigma_{t}$. The covariances herein are zero, as the orthogonalized residuals are independent by construction;

$$
\Sigma_{t} \equiv\left(\begin{array}{cccc}
\sigma_{1 t}^{2} & 0 & 0 & 0 \\
0 & \sigma_{2 t}^{2} & 0 & 0 \\
0 & 0 & \sigma_{3 t}^{2} & 0 \\
0 & 0 & 0 & \sigma_{4 t}^{2}
\end{array}\right)
$$

By recursively writing out equations, it is possible to express the elements of $K_{t-1}$ as functions of elements in the covariance matrix of the residuals, $H_{t}$ :

$$
\begin{aligned}
k_{1, t-1} & =\frac{h_{12 t}}{h_{1 t}} \\
k_{2, t-1} & =\frac{h_{13 t}}{h_{1 t}} \\
k_{3, t-1} & =\frac{h_{23 t}+k_{1, t-1}^{2} h_{13 t}}{h_{2 t}-k_{1, t-1}^{2} h_{1 t}} \\
k_{4, t-1} & =\frac{h_{14 t}}{h_{1 t}} \\
k_{5, t-1} & =\frac{h_{24 t}+k_{1, t-1}^{2} h_{14 t}}{h_{2 t}-k_{1, t-1}^{2} h_{1 t}} \\
k_{6, t-1} & =\frac{h_{34 t}+k_{3, t-1}^{2} h_{24 t}+\left(k_{1, t-1} k_{3, t-1}-k_{2, t-1}\right)^{2} h_{14 t}}{h_{3 t}-k_{3, t-1}^{2} h_{2 t}+\left(k_{1, t-1}^{2} k_{3, t-1}^{2}-k_{2, t-1}^{2}\right) h_{1 t}}
\end{aligned}
$$

The covariance matrix of the orthogonalized residuals is calculated from:

$$
\Sigma_{t}=K_{t-1}^{-1} H_{t} K_{t-1}^{\prime-1}
$$

Likewise for the orthogonalized residuals:

$$
e_{t}=K_{t-1}^{-1} \epsilon_{t}
$$




\subsection{Step 3: Country $i$ 's Bond Returns}

We estimate a univariate model for the return on country $i$ 's bond market, $R_{i 5 t}\left(R_{5 t}\right)$ The conditional mean is given as

$$
\begin{aligned}
R_{5 t} & =c_{0}+c_{1} R_{1, t-1}+c_{2} R_{2, t-1}+c_{3} R_{3, t-1}+c_{4} R_{4, t-1}+c_{5} R_{5, t-1} \\
& +\gamma_{1 t} e_{1 t}+\gamma_{2 t} e_{2 t}+\gamma_{3 t} e_{3 t}+\gamma_{4 t} e_{4 t}+e_{5 t}
\end{aligned}
$$

The conditional variance of the residual, $\operatorname{Var}_{t-1}\left(e_{5 t}\right)=\sigma_{5 t}^{2}$, is assumed to evolve according to the (GJR-) GARCH(1,1) model, cf. (5) above. ${ }^{4}$

To account for possible serial correlation, the one-period lagged own return is included in the mean. Moreover, the return on country $i$ 's bond market depends on last period's return on the US and European stock and bond markets, $R_{1, t-1}, \ldots, R_{4, t-1}$. This is denoted mean-spillover effects in the literature.

The return on the individual bond market also depends on the contemporaneous idiosyncratic shocks to the US and European bond and stock markets, $e_{1 t}, \ldots, e_{4 t}$. As we shall see shortly, these terms represent volatilityspillover effects.

The volatility-spillover parameters, $\gamma_{1 t}, \ldots \gamma_{4 t}$, are time-varying; they take on different, yet constant, values before and after the launch of the euro on January 1, 1999:

$$
\gamma_{i t}=\gamma_{0 i}+\gamma_{1 i} d_{t} i=1,2,3,4
$$

where $d_{t}$ is an indicator function that equals zero before the euro and unity after. Thus, the mean equation now reads:

$$
\begin{aligned}
R_{5 t} & =c_{0}+c_{1} R_{1, t-1}+c_{2} R_{2, t-1}+c_{3} R_{3, t-1}+c_{4} R_{4, t-1}+c_{5} R_{5, t-1} \\
& +\left(\gamma_{01}+\gamma_{11} d_{t}\right) e_{1 t}+\left(\gamma_{02}+\gamma_{12} d_{t}\right) e_{2 t} \\
& +\left(\gamma_{03}+\gamma_{13} d_{t}\right) e_{3 t}+\left(\gamma_{04}+\gamma_{14} d_{t}\right) e_{4 t}+e_{5 t}
\end{aligned}
$$

The sign of $\gamma_{1 i}$ determines whether the $i$ 'th volatility-spillover effect has become weaker or stronger after the introduction of the euro. Some volatilityspillover effects may have become weaker while others may have become stronger.

\footnotetext{
${ }^{4} \mathrm{As}$ is often the case for bond returns, the asymmetry turns out to be insignificant.
} 
Firstly, it is desirable that the volatility-spillover parameters change size at stochastic points in time. Secondly, it is preferable that the direction of the change may be different across the parameters. The present specification in (14) fulfills only the second requirement. The first requirement could be met by using a regime switching model where the regimes are determined by the size of the volatility-spillover parameters $\left(\gamma_{s_{i t=0}} \leq \gamma_{s_{i t=1}}\right)$. For the second demand to be met the volatility-spillover effects should not necessarily be in the same regime at the same time, thereby yielding $2^{4}=16$ different states which makes estimation infeasible. Here, we have given priority to the latter feature.

\subsection{Step 4: Country i's Stock Returns}

The return on country $i$ 's stock index, $R_{6 t}$, is described by a model equivalent to the one for country $i$ 's bond market with two additional explanatory variables: Own country bond market lagged return $\left(R_{6, t-1}\right)$ and own country contemporaneous idiosyncratic shock $\left(e_{5 t}\right)$.

$$
\begin{aligned}
R_{6 t} & =d_{0}+d_{1} R_{1, t-1}+d_{2} R_{2, t-1}+d_{3} R_{3, t-1}+d_{4} R_{4, t-1}+d_{5} R_{5, t-1}+d_{6} R_{6, t-1} \\
& +\delta_{1 t} e_{1 t}+\delta_{2 t} e_{2 t}+\delta_{3 t} e_{3 t}+\delta_{4 t} e_{4 t}+\delta_{5 t} e_{5 t}+e_{6 t}
\end{aligned}
$$

The conditional variance of the residual, $\operatorname{Var}_{t-1}\left(e_{6 t}\right)=\sigma_{6 t}^{2}$, is assumed to evolve according to the (GJR-) GARCH $(1,1)$ process specified above in $(5) .^{5}$

The return on country $i$ 's stock market depends on own lagged return, and last period's return on the US and European bond and stock markets as well as on own bond market lagged return. The terms on the top right hand side of (17) represent the mean-spillover effects from the other bond and stock markets into the stock market of the country in question. The terms on the bottom right hand side of (17) represent the equivalent variance-spillover effects. Here the explanatory variables are the contemporaneous idiosyncratic shocks form the other markets, $e_{1 t}, \ldots, e_{5 t}$.

Again, the volatility-spillover parameters are time varying according to equation (13):

$$
\delta_{i t}=\delta_{0 i}+\delta_{1 i} d_{t} i=1,2,3,4
$$

\footnotetext{
${ }^{5}$ Even for the stock returns, the asymmetry is insignificant.
} 
so that they take on different values before and after the euro:

$$
\begin{aligned}
R_{6 t} & =d_{0}+d_{1} R_{1, t-1}+d_{2} R_{2, t-1}+d_{3} R_{3, t-1}+d_{4} R_{4, t-1}+d_{5} R_{5, t-1}+d_{6} R_{6, t-1} \\
& +\left(\delta_{01}+\delta_{11} d_{t}\right) e_{1 t}+\left(\delta_{02}+\delta_{12} d_{t}\right) e_{2 t}+\left(\delta_{03}+\delta_{13} d_{t}\right) e_{3 t} \\
& +\left(\delta_{04}+\delta_{14} d_{t}\right) e_{4 t}+\left(\delta_{05}+\delta_{15} d_{t}\right) e_{5 t}+e_{6 t}
\end{aligned}
$$

\subsection{Volatility-spillover effects}

The unexpected return on country $i$ 's bond market is given as follows:

$$
\epsilon_{5 t}=\gamma_{1 t} e_{1 t}+\gamma_{2 t} e_{2 t}+\gamma_{3 t} e_{3 t}+\gamma_{4 t} e_{4 t}+e_{5 t}
$$

The first four terms are independent by construction, and the last term contains any remaining effects when we have taken account of the shocks from the US and European bond and stock markets, and is thus also independent here from. Therefore, the conditional variance of the unexpected return is simply the sum of the variances of the different terms: ${ }^{6}$

$$
h_{5 t}=\gamma_{1 t}^{2} \sigma_{1 t}^{2}+\gamma_{2 t}^{2} \sigma_{2 t}^{2}+\gamma_{3 t} \sigma_{3 t}^{2}+\gamma_{4 t}^{2} \sigma_{4 t}^{2}+\sigma_{5 t}^{2}
$$

Thus, the variance of the unexpected return of the individual national bond market depends on the idiosyncratic variances on US and European bond and stock markets as well as own idiosyncratic variance. Thus, the term volatility-spillover effects.

Equivalently, for country $i$ 's stock index the unexpected return is

$$
\epsilon_{6 t}=\delta_{1 t} e_{1 t}+\delta_{2 t} e_{2 t}+\delta_{3 t} e_{3 t}+\delta_{4 t} e_{4 t}+\delta_{5 t} e_{5 t}+e_{6 t}
$$

By the same arguments, the conditional variance of the unexpected return depends on the idiosyncratic variances of US and European bond and stock markets as well as own idiosyncratic bond and stock variances.

$$
h_{6 t}=\delta_{1 t}^{2} \sigma_{1 t}^{2}+\delta_{2 t}^{2} \sigma_{2 t}^{2}+\delta_{3 t}^{2} \sigma_{3 t}^{2}+\delta_{4 t}^{2} \sigma_{4 t}^{2}+\delta_{5 t}^{2} \sigma_{5 t}^{2}+\sigma_{6 t}
$$

\footnotetext{
${ }^{6}$ Equivalent expressions exist for the various conditional covariances (not shown).
} 


\subsection{Variance Ratios}

It is possible to calculate "variance ratios" using the estimated parameters. Using (19) we calculate the proportion of the variance of the unexpected return of country $i$ 's bond return that is caused by the five different factors: US bond market effects, US stock market effects, European bond market effects, European stock market effects, and own bond market effects.

$$
\begin{aligned}
V R_{1 t} & =\frac{\hat{\gamma}_{1 t}^{2} \hat{\sigma}_{1 t}^{2}}{\hat{h}_{5 t}} \\
V R_{2 t} & =\frac{\hat{\gamma}_{2 t}^{2} \hat{\sigma}_{2 t}^{2}}{\hat{h}_{5 t}} \\
V R_{3 t} & =\frac{\hat{\gamma}_{3 t}^{2} \hat{\sigma}_{3 t}^{2}}{\hat{h}_{5 t}} \\
V R_{4 t} & =\frac{\hat{\gamma}_{4 t}^{2} \hat{\sigma}_{4 t}^{2}}{\hat{h}_{5 t}} \\
V R_{5 t} & =\frac{\hat{\sigma}_{5 t}^{2}}{\hat{h}_{5 t}}
\end{aligned}
$$

For country $i$ 's stock market the origin of the first four effects is unaltered, then there are own bond market effects, and own stock market effects. Otherwise, the variance ratios are calculated as for the bond market.

$$
\begin{aligned}
V R_{1 t}^{*} & =\frac{\hat{\delta}_{1 t}^{2} \hat{\sigma}_{1 t}^{2}}{\hat{h}_{6 t}} \\
V R_{2 t}^{*} & =\frac{\hat{\delta}_{2 t}^{2} \hat{\sigma}_{2 t}^{2}}{\hat{h}_{6 t}} \\
V R_{3 t}^{*} & =\frac{\hat{\delta}_{3 t}^{2} \hat{\sigma}_{3 t}^{2}}{\hat{h}_{6 t}} \\
V R_{4 t}^{*} & =\frac{\hat{\delta}_{4 t}^{2} \hat{\sigma}_{4 t}^{2}}{\hat{h}_{6 t}} \\
V R_{5 t}^{*} & =\frac{\hat{\delta}_{5 t}^{2} \hat{\sigma}_{5 t}^{2}}{\hat{h}_{6 t}} \\
V R_{6 t}^{*} & =\frac{\hat{\sigma}_{6 t}}{\hat{h}_{6 t}}
\end{aligned}
$$




\section{Data Description}

We obtain bond and stock indices for the US, Europe, and the following nine European Union countries: Belgium, Denmark, France, Germany, Italy, the Netherlands, Spain, Sweden, and the United Kingdom. Total return indices imply that the received coupons (dividends) are reinvested into the bonds (stocks) of the index. Log-returns are calculated as the logarithmic growth rate of the indices.

As to bonds, we apply the J. P. Morgen government bond indices obtained from DataStream. The aggregate European index is a value weighted average of the indices of the nine individual indices. As to stocks, we apply the DataStream equity indices. The aggregate European index covers all 15 EU countries.

The returns are counted in local currency. There are a number of reasons for using local currency returns (in contrast to common currency returns). Local currency returns are equivalent to currency hedged returns, and it is both easy and inexpensive to hedge currency risk. Local currency returns are relevant for analyzing economic fundamentals. Miyakoshi (2003) in his study of volatility spillover on equity markets argues for local currency returns, because e.g. De Santis and Gérard (1998) find that currency risk is highly important for stock returns. Ilmanen (1995) argues that one should count bond returns in local currency to separate bond market predictability from foreign exchange market predictability, because exchange rates are more volatile than bond returns.

The weekly data (recorded on Wednesdays) cover the period from January 6, 1988 to December 3, 2003. Thus, there are 831 observations in our sample period.

We use data of a fairly low (weekly) frequency, although they are available at a higher (daily) frequency, in order to remedy the potential problem of using non-synchronous data, cf. Burns and Engle (1998). Moreover, Martens and Poon (2001) find that close-to-close (non-synchronous) returns on international stock markets tend to underestimate the true correlations. This is taken as evidence that using non-synchronous returns will tend to accept the null hypothesis of no cross market relation too often, thus being a conserva- 
tive strategy for analysis.

Table 1 contains various descriptive statistics for the bond and stock indices. Except for Italy, the average bond return is smaller than the average stock return, e.g. for aggregate Europe the average returns are $0.16 \%$ and $0.20 \%$ for bonds and stocks, respectively. Equivalently, the standard deviation is much larger for stock returns than for bond returns; for aggregate Europe compare $0.50 \%$ to $2.25 \%$. As is usual for financial returns, the series are (with two exceptions) skewed to the left and show excess kurtosis. The return series show only weak signs of autocorrelation. The squared return series are significantly autocorrelated, i.e. providing signs of heteroskedasticity.

The bond and stock markets of a given country are positively correlated (except for the Netherlands); the average correlation coefficient amounts to 0.14. The average correlation between the countries' bond markets is 0.65 and slightly lower for the stock markets, 0.64 . The average correlation between the aggregate European bonds (stocks) and the countries' bonds (stocks) is $0.82(0.80)$. The average correlation between the US bonds (stocks) and the individual bonds (stocks) is 0.45 (0.59). The correlations between the aggregate European bonds (stocks) and the individual stocks (bonds) are positive apart from the Netherlands (positive), averaging 0.08 (0.06). The correlations between the US bonds (stocks) and the individual stocks (bonds) are negative (positive), averaging -0.08 (0.05).

Overall, the simple correlation coefficients indicate that the aggregate European financial markets exert more influence on the individual European markets than do the US markets. Not surprisingly, the simple correlation coefficients indicate that the influence going from bonds to stocks and vice versa is smaller than the influence going from bonds to bonds and from stocks to stocks.

Granger causality tests with 4 lags are applied. The individual bond markets either Granger cause the stock markets (Belgium, the Netherlands, Spain, Sweden, and the UK), or neither one Granger causes the other (Denmark, France, Germany, and Italy). The European bond market Granger causes the European stock market. The US bond and the US stock markets do not Granger cause each other. Thus, Granger causality tests support 
letting the influence go from the bond markets to the stock markets. Still, as a robustness check we also investigate the results arising from letting the influence go from stock markets to bond markets.

The US bond market neither Granger causes nor is Granger caused by the European bond or stock market. The US stock market is Granger caused by both the European bond and the European stock markets. Thus, it is not clear from Granger causality tests that the model should allow only the US markets to influence the European markets and not vice verse. Therefore, we also investigate a model setup where aggregate Europe exerts influence on the US instead of the other way round.

As we analyze the log-returns (i.e. the first differences of the log-prices) in a multivariate framework it matters whether the log-prices cointegrate. Applying the Johansen procedure to the log-prices of the US bonds, US stocks, European bonds, and European stocks (the four series included in the first step of the estimation) we find that there is one cointegrating relation. For one country at a time, we investigate the cointegration between the four above-mentioned series as well as that country's stock and bond log-prices. For all countries, the six series cointegrate and furthermore there is evidence that we can leave out the country specific series from the cointegrating relation. Thus, in the empirical analysis we include the following cointegrating relation (lagged one period) as an additional explanatory variable in the mean equations, i.e. in equations (1), (12), (14), (15), and (17): ${ }^{7}$

$$
z_{t}=\ln \left(P_{1 t}\right)-2.487 \ln \left(P_{2 t}\right)-\ln \left(P_{3 t}\right)+2.941 \ln \left(P_{4 t}\right)+\text { constant }
$$

The error correction term is included in the mean equations to account for the attraction between the log-price levels. The empirical results yet to be presented do not hinge on $z_{t-1}$ being included as explanatory variable.

\footnotetext{
${ }^{7}$ For the cointegrating relation we cannot reject that the hypothesis of unit coefficients (of opposite signs) for the two bond series. The coefficients for the stocks are significantly different in absolute size.
} 


\section{Empirical Analysis}

We open the empirical section by presenting the results from estimating the volatility-spillover model. Thereafter (in Section 4.2) we discuss the empirical variance ratios. Sensitivity analysis is provided in Section 4.3.

\subsection{Model Estimates}

The volatility-spillover model described in Section 2 is estimated using the Quasi Maximum Likelihood method with Gaussian likelihood functions. The estimation is conducted using a combination of the Berndt, Hall, Hall and Hausman (1974) and the Newton-Raphson numerical optimization algorithm. The estimation is conducted in GAUSS using the Constrained Maximum Likelihood module.

Table 2 reports the results from estimating the volatility-spillover model. ${ }^{8}$ For brevity, only the parameter estimates are provided together with an indication of their significance based on the Bollerslev and Wooldridge (1992) robust standard errors.

Panel A of Table 2 shows the parameter estimates of the multivariate GARCH model for the US bond return, the US stock return, the European bond return, and the European stock return laid out in equations (1)-(5). Thus, Panel A concern the first step of the model.

Although we find only weak signs of autocorrelation in the summary statistics, cf. Table 1, we cannot assume constant means; the robust Wald test of the null hypothesis that $\Phi_{1}=0$ is strongly rejected (i.e. the $\operatorname{VAR}(1)$ parameter matrix is not zero). Also, the cross effects are significant. We reject the null hypothesis of an $\mathrm{AR}(1)$ model instead of the $\operatorname{VAR}(1)$ model (i.e. $\Phi_{1}$ is not diagonal).

Asymmetry effects are present in the variance of the stock returns; negative shocks have more effect than positive shocks. For bonds, the variance processes are symmetrical and therefore in the reported results, $\alpha_{1}^{*}$ and $\alpha_{3}^{*}$ are set equal to zero. The conditional variance processes are rather persistent, meaning that shocks to them die out slowly. The observed volatility features

\footnotetext{
${ }^{8}$ The log-returns are not transformed into percentage returns.
} 
are typical for the GARCH literature.

The conditional correlations are time-varying according to equation (4). The point estimates of the weighting parameters for the conditional correlation matrix $\left(\theta_{1}\right.$ and $\left.\theta_{2}\right)$ equal 0.975 and 0.022 , respectively. They are of about the same size as in the four applications in Tse and Tsui (2002). The large value of $\theta_{1}$ (close to unity) implies that the correlation process is highly persistent. The hypothesis that $\theta_{1}=\theta_{2}=0$ is strongly rejected, in other words the conditional volatilities are not constant as specified by the CCCOR model. The constant part of the correlation matrix, $\Gamma$, includes only positive correlations, but only half of them are significant; (US stocks; US bonds), (US bonds; European bonds), and (US stocks; European stocks).

Figure 1 shows the time-series evolution of the conditional correlations. For the entire sample period the conditional correlation between the US bond return and European bond return is positive and the same applies for the stock-stock correlation. In the beginning and end of the sample the bond-bond and stock-stock correlations are fairly high (around 0.70), whereas they are somewhat smaller in the middle period (around 0.45 and 0.55, respectively). They reach a local minimum around 1993 where the bond-bond correlation drops to a lower level than the stock-stock correlation, minimum values are 0.17 and 0.42 , respectively. The four time series of bondstock correlations all start out being positive and then begin to decrease around 1997. Beginning in 1999, the stock-bond correlations turn negative. Thus, the conditional correlations from the DCC model provide results that are consistent with the moving window correlations in Ilmanen (2003)

Table 3 shows average conditional volatilities. The top part concerns the US and European markets. The first two columns concern the conditional standard deviations of the idiosyncratic shocks (i.e. the orthogonalized residuals), denoted $\sigma_{j t}^{2}$. The last two columns concern the conditional variance of the "raw" residuals, denoted $h_{j t}$. The conditional volatilities are much larger for the stocks than for the bonds. The conditional variances of the orthogonalized residuals are different from the conditional variances of the raw residuals, except for $j=1$. Thus, the ordering of the residuals during the orthogonalization might influence subsequent results that make use of the conditional variances of the orthogonalized residuals. Unfortunately, 
principal components analysis does not provide us with a natural ordering of the residuals. ${ }^{9}$

Panel B of Table 2 shows the parameter estimates arising from estimating the model for the individual countries' bond returns given in equation (14). Panel B is thereby concerned with the third step of the model.

The variance processes are not significantly asymmetric, so this feature is excluded from the model specification. The GARCH processes are highly persistent.

The expected bond returns are influenced by lagged returns - both own lagged returns and lagged returns for the US and European bond and stock markets. The dependence of the bond return today on lagged US and European returns is denoted mean-spillover effects in the literature. Not all the mean-spillover parameters $\left(c_{i 1}, \ldots, c_{i 4}\right)$ are significant for all countries, but all parameters are significant for some countries. There does not seem to be a pattern for the structure of the mean-spillover effects, i.e. which countries receive mean-spillover effects from which markets.

In equation (14) the lagged cointegrating relation, $z_{t-1}$ given by equation (24), is added as explanatory variable to take account of the attraction of the log-price levels. The coefficients are negative, significant, and numerically small.

There are significant volatility-spillover effects at play at the bond markets. For the period before the euro, there are positive and strongly significant volatility-spillover effects to the individual bond markets from the US bond market, the US stock market, and the European bond market. This applies to all the countries under investigation. The volatility spillover parameters for the European stock market $\left(\gamma_{04}\right)$ are negative or insignificant, thereby indicating that there is no volatility-spillover from the aggregate European stock market into the individual bond markets. The volatility-spillover parameters for the European bond market are the largest, $\overline{\hat{\gamma}}_{03} \approx 0.77$. The volatility-spillover parameters for the US bond market are also fairly large, $\overline{\hat{\gamma}}_{01} \approx 0.41$, whereas the volatility-spillover parameters for the US stock mar-

\footnotetext{
${ }^{9}$ The first $\mathrm{PC}$ is close to being an equally weighted average of the four residuals, the second PC loads negatively on bond residuals and positively on stock residuals, and the third PC loads positively on the US residuals and negatively on European residuals.
} 
ket are much lower, $\overline{\hat{\gamma}}_{02} \approx 0.12$.

The nature of the volatility spillover has changed by the introduction of the euro: $\gamma_{11}=\gamma_{12}=\gamma_{13}=\gamma_{14}=0$ is strongly rejected. After the euro, there are significant volatility-spillover effects to the individual bond markets from the US bond market, and the European bond market; the hypotheses that $\gamma_{01}+\gamma_{11}=0$ and $\gamma_{03}+\gamma_{13}=0$ are rejected for all countries. The volatilityspillover effect from the US stock market has ceased to be important $\left(\gamma_{02}+\gamma_{12}\right.$ is small and negative) and the volatility-spillover effect from the European stock market is still insignificant. The influence from the US bond market and the European bond market are strengthened by the introduction of the euro.

Panel $\mathrm{C}$ of Table 2 provides the parameter estimates of the model for the individual stock returns in equation (11). Panel $\mathrm{C}$ deals with the fourth step of the model.

Many of the patterns from the bond markets are recovered. There are significant mean-spillover effects into the individual stock markets. The mean spillover parameters $\left(d_{i 1}, \ldots, d_{i 5}\right)$ are not all significant for all countries. The returns depend significantly and negatively on the lagged cointegrating equation. The variance processes are highly persistent and show no signs of asymmetry which is somewhat unusual for stock returns.

For the period before the euro, there are significant volatility-spillover effects into the individual stock markets from the US bond market, the US stock market, the European bond market, and from own bond market. The volatility spillover coefficients are largest for the European bond market $\left(\delta_{03}\right)$, and smallest for the own bond market $\left(\delta_{05}\right)$.

The volatility-spillover effects are significantly influenced by the introduction of the euro; we strongly reject that $\delta_{11}=\delta_{12}=\delta_{13}=\delta_{14}=\delta_{15}=0$ by robust Wald tests. After the euro, there is significant volatility-spillover from the US stock market and the European stock market into the individual stock markets. The pre-euro volatility-spillover coefficients are negative for the US bond market, the European bond market, and own bond market; $\left(\hat{\delta}_{0 i}+\hat{\delta}_{1 i}<0\right)$ for $i=1,3,5$. The volatility-spillover effects from the US stock market are diminished, whereas the effects from the European stock market are increased. 
The bottom part of Table 3 shows the average conditional standard deviation for country $i$ 's residuals in equation (14) and (16), denoted $\sigma_{i 5 t}^{2}$ and $\sigma_{i 6 t}^{2}$, respectively as well as the average conditional volatility for country $i$ 's unexpected returns in equations (17) and (19), denoted $h_{i 5 t}$ and $h_{i 6 t}$, respectively. The conditional volatilities of the unexpected returns are much larger than the conditional volatilities of the residuals. This is not at all surprising as the volatility of the residuals is one of several components of the volatilities of the unexpected returns, cf. equations (18) and (20).

The volatility-spillover model appears to provide an adequate description of the data. The properties of the standardized residuals are investigated (separately for each estimation step) and we hardly find any signs of remaining autocorrelation or heteroskedasticity. ${ }^{10}$

\subsection{Empirical Variance Ratios}

From the significance of the volatility-spillover coefficients we conclude above that until 1999 there are significant volatility-spillover effects from the US bond, US stock, and European bond markets into the individual bond markets and after 1999 only from the US bond and European bond markets. Similarly, before 1999 there are significant volatility-spillover effects from the US bond, US stock, European bond, and own bond markets into the national stock markets and after 1999 only from the US stock and European stock markets. However, so far we have not discussed the order of magnitude of the spillover effects. The variance ratios described in Section 2.6 enable us to measure the importance of the various markets in this respect. Table 4 shows the average variance ratios, at the top for the bond markets, and at the bottom for stock markets. The averages have been calculated for the two sub periods divided by the introduction of the euro. ${ }^{11}$

\footnotetext{
${ }^{10}$ For the standardized residuals from the first step of the model we investigate the autocorrelation of the residuals, the squared residuals, and the cross-multiplied residuals. For the third and fourth step, we investigate the autocorrelation of the residuals and the squared residuals. In total, we only find significant autocorrelation in one instance.

${ }^{11} \mathrm{~A}$ separate appendix (available upon request) provides various figures of the variance ratios. In particular, for each country's bond market a figure shows the evolution of the five time series of the variance ratios. Similarly, for each country's stock market a figure
} 
First we analyze the individual bond markets in the period before the euro. The volatility-spillover effects from the aggregate European bond market and the own bond market are the largest effects; on average the variance of the European idiosyncratic shock accounts for between 27\% (Spain) and $44 \%$ (the Netherlands) of the variance of the unexpected returns for the individual bond markets; the average of the averages across the countries is $36 \%$. The average own bond market effects provide around $37 \%$ of the variance of the unexpected return for various the bond markets. The proportion of the bond variances caused by US bond effects are also fairly large, and amounts on average to $15 \%$. The US stock market effects are somewhat smaller, around $12 \%$ on average. The European stock market effects are negligible.

After the euro only the bond markets play a role: The European bond markets on average account for around $44 \%$ of the variance of the unexpected return for the national bond markets. The US bond market effect is slightly lower, around $41 \%$. The own bond market effect has decreased dramatically to around $15 \%$ (from around $37 \%$ ).

For the stock markets the magnitudes of the volatility-spillover effects are quite different from the bond markets. Before the euro, the own stock market effects are largest (around $57 \%$ on average) followed by the US stock market effects (on average 31\%). The European and US bond markets also account for a small fraction of the variance of the unexpected stock returns, $8 \%$ and $3 \%$ on average). Both the European stock effects and the own-country bond effects are negligible. After the introduction of the euro, only the stock market effects are relevant; the own stock market effects is the dominant factor (48\% on average), the US stock market effects are also strong (31\%), and the European stock market effects are much stronger than before the euro ( $13 \%$ on average).

Overall, the sizes of the variance ratios tell us that after the introduction of the euro the countries' bond markets work almost autonomously from the world and regional stock markets with respect to variance. Similarly, after the euro the countries' stock markets are hardly influenced by the world and regional bond markets with respect to variance. For the period before the euro, the results are less clearcut. For the bond markets, the own market shows the evolution of the six time series of the variance ratios. 
effects have decreased dramatically after the launch of the euro, while the decrease has been weaker for the stock markets.

\subsection{Sensitivity Analysis}

The ordering of the residuals in the orthogonalization most likely influence the empirical results. Therefore, we investigate alternatives to the "original" ordering of the residuals where the influence flows from the US markets to European markets and from bond markets to stock markets.

As a start, the influence goes from the European markets to the US markets, i.e. from the regional markets to the global markets, although it appears counterintuitive. We re-estimate the volatility-spillover model from Section 2 with the following modification: $R_{1 t}, R_{2 t}, R_{3 t}$, and $R_{4 t}$ now refer to the European bond return, the European stock return, the US bond return, and the US stock return, respectively. Invariably, $R_{i 5 t}$ and $R_{i 6 t}$ are country $i$ bond return and country $i$ stock return. To save space the parameter estimates are not stated. Table 5 shows the average variance ratios based hereon.

Concerning the variance of the unexpected bond returns in the period before the euro, the main differences to the first specification is that the European bond effects are remarkedly stronger now, on average $61 \%$. In contrast, the US effects are much smaller, in fact they are negligible. The size of the own bond effects are almost unaltered. For the period after the euro, the aggregate European bond effect is even stronger; for the eurozone countries and Denmark it amounts to $96 \%$ on average. ${ }^{12}$ For the nonEMU countries Sweden and the UK the aggregate European effect has also increased, but to a lower level (73\%) and consequently, their own bond market effect has not declined as much as for the EMU-countries. The unmentioned effects remain negligible as in the original specification.

As to the variance of the unexpected stock returns for the period before the euro, the European stock effect has gained importance compared to the original model, averaging $41 \%$. This increase is at the expense of the US stock

\footnotetext{
${ }^{12}$ Due to the tight pecking of the Danish Krone to the euro, for practical purposes Denmark is regarded an EMU-member country.
} 
effect which is now very small. The own stock effect has dropped slightly, to an average of $46 \%$. The only other sizeable effect is the European bond effect which averages $13 \%$. After the introduction of the euro, the European stock market effect has become stronger (57\%), and the European bond effect weaker $(4 \%)$. With a couple of exceptions, the importance of the own stock market effect has decreased after the euro.

Comparing the results in Table 4 and Table 5 we see that it matters which way the model specify the direction of the influence. The US effects appear to be unrealistically small when the influence goes from aggregate Europe to the US. Therefore we find it advisable to use the original specification where the influence moves from the global markets to the regional markets.

We also investigate the effects of letting the influence flow from the stock markets to the bond markets. Thus, once again we re-estimate the volatilityspillover model with one modification, namely the following: $R_{1 t}, R_{2 t}, R_{3 t}$, $R_{4 t}, R_{i 5 t}$, and $R_{i 6 t}$ now refer to the US stock return, the US bond return, the European stock return, the European bond return, country $i$ stock return, and country $i$ bond return, respectively. The model is invariably specified such that the US markets influence the aggregated European markets which again influences the individual European markets. Table 6 shows the resulting average variance ratios.

For the variance ratios applying in the period before the euro for the unexpected stock returns the proportion explained by the European stock effect increases a lot compared to the first specification (on average 31\%). The US stock effect as well as the own country stock effect loose importance (averages of $21 \%$ and $44 \%$, respectively). After the euro, the own stock market effect is weaker than in the original specification (36\%) whereas the US and European stock market effects are stronger (38\% and $23 \%$ respectively). As previously, the variance of the unexpected stock return is almost exclusively influenced by the stock markets.

Regarding the variance of the unexpected bond returns before the euro, the European bond effect ceases to be important in comparison to the first specification, whereas the US bond effect is more important (on average 19\%). The own bond market effect is much stronger than in the first specification (averaging 68\%). After the introduction of the euro, only bond effects are 
present with the US and European bond effects being the strongest (35\% and $35 \%$, respectively). The own bond market effect is diminished after the euro (on average $26 \%$ ) which is much higher than in the original (bond $\rightarrow$ stock) specification.

The bond markets appear to exert more influence than the stock markets when they are placed first in the model and vice verse. Our empirical findings do not enable us to decide unambiguously which of the two is the better model assumption. However, we tend to find the results from the original specification more convincing. Moreover, we rely on economic intuition to conclude that it is more reasonable that the stock markets are under influence by the bond markets rather than vice versa, cf. the discussion in Section 2.2.

\section{Conclusion}

We have (we believe) added to the literature model-wise as well as empirically by analyzing bond and equity volatility-spillover effects simultaneously.

We have applied a new volatility-spillover model. The model has included volatility spillover into national European bond and equity markets from the US and aggregate European bond and equity markets. The conditional variance of the unexpected return of country $i$ 's bond market has been decomposed into separate effects caused by contemporaneous idiosyncratic US bond variance, idiosyncratic US stock variance, idiosyncratic European bond variance, idiosyncratic European stock variance, and own bond market idiosyncratic variance. The conditional variance of the unexpected return of country $i$ 's stock market has been decomposed into the same five effects as well as idiosyncratic own stock market variance.

We have investigated nine European countries' bond and stock markets. We have found significant volatility-spillover into the individual bond and equity markets from the global and regional bond and equity markets. Our results have indicated that bond (stock) market volatility is mainly influenced by bond (stock) market effects. Local, regional, and global effects have all been found to be of importance for European bond and stock volatility. We have accounted for the structural break caused by the introduction of the euro. 


\section{References}

Antell, J. (2004), Volatility Linkages in the Finnish Stock, Bond, and Money Markets, Working Paper, Swedish School of Economics and Business Administration.

Baele, L. (forthcoming), 'Volatility Spillover Effects in European Equity Markets: Evidence from a Regime Switching Model', Journal of Financial and Quantitative Analysis .

Baele, L., Ferrando, A., Hördahl, P., Krylova, E. and Monnet, C. (2004), Measuring Financial Integration in the Euro Area, Occasional Paper, European Central Bank.

Bauwens, L., Laurent, S. and Rombouts, J. V. K. (2003), Multivariate GARCH Models: A Survey, Working Paper, Universite Catholique de Louvain.

Bekaert, G. and Harvey, C. R. (1997), 'Emerging Equity Market Volatility', Journal of Financial Economics 43, 29-77.

Bekaert, G., Harvey, C. R. and Ng, A. (forthcoming), 'Market Integration and Contagion', Journal of Business .

Berndt, E. K., Hall, B. H., Hall, R. E. and Hausman, J. A. (1974), 'Estimation and Inference in Nonlinear Structural Models', Annals of Economic and Social Measurement 3, 653-665.

Bollerslev, T. (1990), 'Modelling the Coherence in Short-Run Nominal Exchange Rates', Review of Economics and Statistics 72, 498-505.

Bollerslev, T. and Wooldridge, J. M. (1992), 'Quasimaximum Likelihood Estimation Dynamic Models with Time Varying Covariances', Econometric Reviews 11, 143-172.

Burns, P. and Engle, R. (1998), 'Correlations and Volatilities of Asynchronous Data', Journal of Derivatives 5(4), 7-18. 
Campbell, J. Y. and Ammer, J. (1993), 'What Moves the Stock and Bond Markets? A Variance Decomposition for Long-Term Asset Returns', Journal of Finance 48(1), 3-37.

Cappiello, L., Engle, R. F. and Sheppard, K. (2003), Asymmetric Dynamics in the Correlations of Global Equity and Bond Returns, Working Paper, European Central Bank.

Christiansen, C. (2003), Volatility-Spillover Effects in European Bond Markets, Working Paper, Aarhus School of Business.

Connolly, R., Stivers, C. and Sun, L. (2004), Commonality in the TimeVariation of Stock-Bond and Stock-Stock Return Comovements, Working Paper, Kenan-Flagler Business School, University of North Carolina at Chapel Hill.

Connolly, R., Stivers, C. and Sun, L. (forthcoming), 'Stock Market Uncertainty and the Stock-Bond Return Relation', Journal of Financial and Quantitative Analysis .

De Santis, G. and Gérard, B. (1998), 'How Big is the Premium for Currency Risk?', Journal of Financial Economics 49, 375-412.

Engle, R. (2002), 'Dynamic Conditional Correlation: A Simple Class of Multivariate Generalized Autoregressive Conditional Heteroskedasticity Models', Journal of Business \&f Economic Statistics 20(3), 339-350.

Engle, R. F., Ito, T. and Lin, W.-L. (1990), 'Meteor-Showers or Heat Waves? Heteroskedastic Intro-Daily Volatility in the Foreign Exchange Market', Econometrica 58(3), 525-542.

Fama, E. F. and French, K. R. (1993), 'Common Risk Factors in the Returns on Stocks and Bonds', Journal of Financial Economics 33, 3-56.

Fleischer, P. (2004), Volatility and Information Linkages across Markets and Countries, Working Paper, Australian National University. 
Fleming, J., Kirby, C. and Ostdiek, B. (1998), 'Information and Volatility Linkages in the Stock, Bond, and Money Markets', Journal of Financial Economics 49, 111-137.

Glosten, L. R., Jagannathan, R. and Runkle, D. E. (1993), 'On the Relation between the Expected Value and the Volatility of the Nominal Excess Return on Stocks', Journal of Finance 48, 1779-1802.

Hartmann, P., Maddaloni, A. and Manganelli, S. (2003), The Euro Area Financial System: Structure, Integration, and Policy Initiatives, Working Paper, European Central Bank.

Ilmanen, A. (1995), 'Time-Varying Expected Returns in International Bond Markets', Journal of Finance 50(2), 481-506.

Ilmanen, A. (2003), 'Stock-Bond Correlations', Journal of Fixed Income $\mathbf{1 3}(2), 55-66$.

Kroner, K. F. and Ng, V. K. (1998), 'Modeling Asymmetric Comovements of Asset Returns', Review of Financial Studies 11(4), 817-844.

Lin, W.-L., Engle, R. F. and Ito, T. (1994), 'Do Bulls and Bears Move across Borders? International Transmission of Stock Returns and Volatility', Review of Financial Studies 7(3), 507-538.

Martens, M. and Poon, S.-H. (2001), 'Returns Synchronization and Daily Correlation Dynamics between International Stock Markets', Journal of Banking \& Finance 25, 1805-1827.

Miyakoshi, T. (2003), 'Spillovers of Stock Return Volatility to Asian Equity Markets from Japan and the US', Journal of International Financial Markets, Institutions, and Money 13, 383-399.

Ng, A. (2000), 'Volatility Spillover Effects from Japan and the US to the Pacific-Basin', Journal of International Money and Finance 19, 207233. 
Tse, Y. K. and Tsui, A. K. C. (2002), 'A Multivariate Generalized Autoregressive Conditional Heteroscedasticity Model with Time-Varying Correlations', Journal of Business and Economic Statistics 20(3), 351-362. 


\begin{tabular}{|c|c|c|c|c|c|c|}
\hline & Mean & Stdev. & $\begin{array}{l}\text { - Bond } \\
\text { Skew. }\end{array}$ & Kurt. & $\mathrm{AC}(1)$ & $\mathrm{AC}^{2}(1)$ \\
\hline US & 0.15 & 0.61 & -0.33 & 3.69 & 0.00 & 0.09 \\
\hline $\mathrm{Eu}$ & 0.16 & 0.50 & -0.67 & 4.70 & 0.01 & 0.12 \\
\hline $\mathrm{Be}$ & 0.15 & 0.50 & -0.53 & 5.03 & -0.01 & 0.19 \\
\hline De & 0.17 & 0.56 & -0.47 & 6.49 & 0.06 & 0.18 \\
\hline $\mathrm{Fr}$ & 0.16 & 0.56 & -0.35 & 4.55 & -0.01 & 0.12 \\
\hline $\mathrm{Ge}$ & 0.12 & 0.49 & -0.71 & 4.84 & 0.03 & 0.11 \\
\hline It & 0.21 & 0.64 & -0.56 & 8.39 & 0.04 & 0.17 \\
\hline $\mathrm{Ne}$ & 0.13 & 0.50 & -0.76 & 5.11 & 0.04 & 0.09 \\
\hline $\mathrm{Sp}$ & 0.19 & 0.60 & -0.26 & 8.18 & 0.02 & 0.18 \\
\hline Sw & 0.18 & 0.71 & -0.19 & 11.39 & -0.03 & 0.09 \\
\hline UK & 0.17 & 0.78 & 0.00 & 4.55 & -0.01 & 0.07 \\
\hline \multicolumn{7}{|c|}{ - Stocks - } \\
\hline & Mean & Stdev. & Skew. & Kurt. & $\mathrm{AC}(1)$ & $\mathrm{AC}^{2}(1)$ \\
\hline US & 0.23 & 2.23 & -0.26 & 4.80 & -0.09 & 0.17 \\
\hline $\mathrm{Eu}$ & 0.20 & 2.25 & -0.38 & 6.15 & -0.07 & 0.33 \\
\hline $\mathrm{Be}$ & 0.18 & 2.35 & -0.16 & 9.26 & -0.08 & 0.39 \\
\hline $\mathrm{De}$ & 0.26 & 2.29 & -0.15 & 4.50 & 0.04 & 0.17 \\
\hline Fr & 0.23 & 2.74 & -0.21 & 5.46 & -0.09 & 0.31 \\
\hline $\mathrm{Ge}$ & 0.17 & 2.70 & -0.55 & 5.71 & -0.07 & 0.25 \\
\hline It & 0.15 & 3.04 & -0.19 & 3.95 & 0.01 & 0.18 \\
\hline $\mathrm{Ne}$ & 0.22 & 2.48 & -0.54 & 9.24 & -0.12 & 0.39 \\
\hline $\mathrm{Sp}$ & 0.21 & 2.67 & -0.42 & 4.42 & -0.03 & 0.17 \\
\hline Sw & 0.25 & 3.40 & -0.18 & 5.80 & -0.06 & 0.12 \\
\hline UK & 0.19 & 2.14 & 0.13 & 6.37 & -0.05 & 0.28 \\
\hline
\end{tabular}

The table reports summary statistics for the weekly returns (in \%) of the J. P. Morgen government bond indices and the DataStream stock indices for the US, Europe (Eu), Belgium (Be), Denmark (De), France (Fr), Germany (Ge), Italy (It), the Netherlands (Ne), Spain (Sp), Sweden (Sw), and the UK. The following statistics are reported: Mean, standard deviation, skewness, kurtosis, first order autocorrelation, and first order autocorrelation of the squared variable.

Table 1: Summary Statistics 


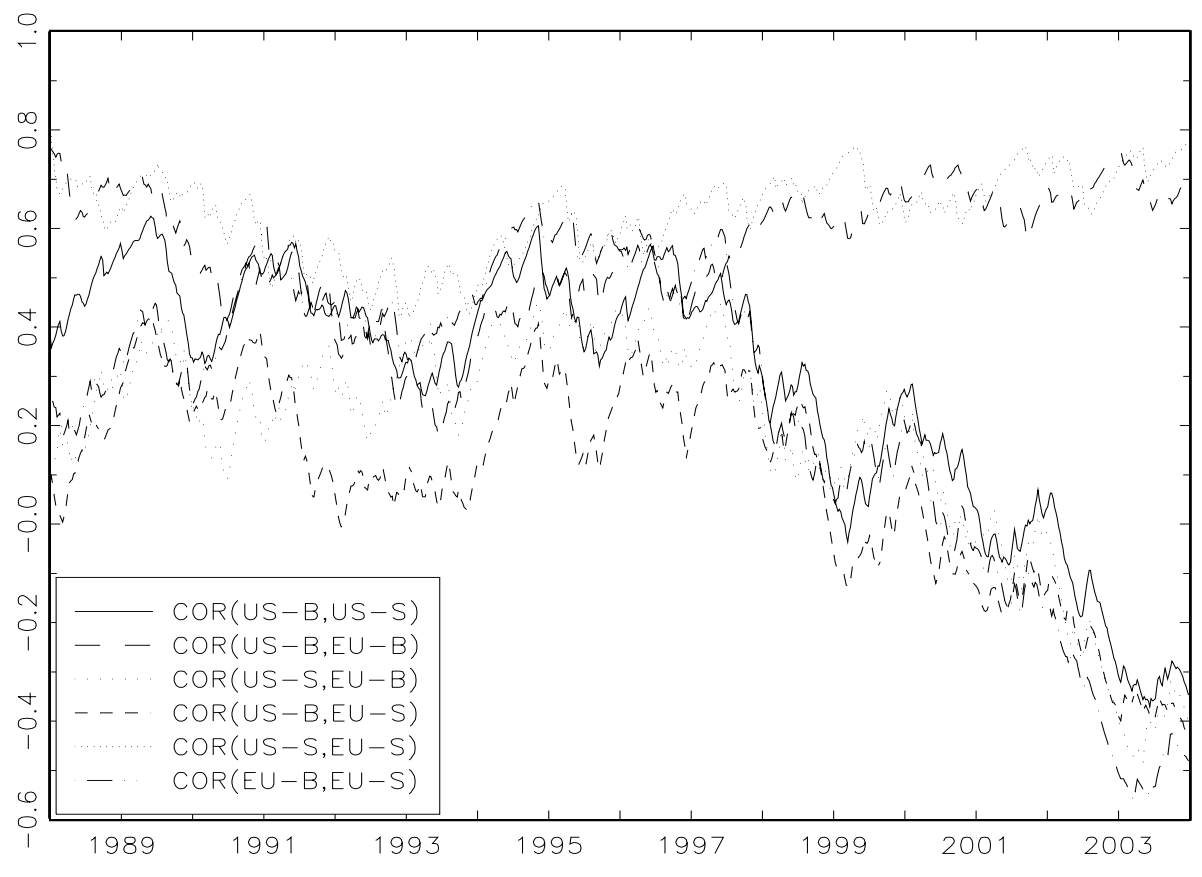

Figure 1: DCC Correlations 
Panel A: US and European Bond and Stock Returns

\begin{tabular}{|c|c|c|c|c|c|}
\hline & & $R_{1 t}$ & $R_{2 t}$ & $R_{3 t}$ & $R_{4 t}$ \\
\hline$\Phi_{0}$ & & 0.002 & -0.001 & $-0.009^{* * *}$ & -0.014 \\
\hline \multirow[t]{4}{*}{$\Phi_{1}$} & $R_{1 t-1}$ & -0.036 & 0.207 & $0.080^{* * *}$ & 0.117 \\
\hline & $R_{2 t-1}$ & -0.007 & $-0.147 * * *$ & -0.017 & -0.008 \\
\hline & $R_{3 t-1}$ & 0.074 & 0.187 & -0.005 & 0.111 \\
\hline & $R_{4 t-1}$ & -0.015 & 0.065 & 0.015 & 0.009 \\
\hline$\Phi_{2}$ & $z_{t-1}$ & 0.0005 & -0.001 & $-0.005^{* * *}$ & 0.008 \\
\hline$\omega$ & & $2 \cdot 10^{-6 * * *}$ & $0.002^{* *}$ & $7 \cdot 10^{-7 * * *}$ & $0.002^{* *}$ \\
\hline$\alpha$ & & $0.060^{* * *}$ & 0.000 & $0.047^{* * *}$ & $0.043^{*}$ \\
\hline$\alpha^{*}$ & & & $0.161^{* * *}$ & & $0.089^{* *}$ \\
\hline$\beta$ & & $0.887 * * *$ & $0.856^{* * *}$ & $0.918^{* * *}$ & $0.850^{* * *}$ \\
\hline \multirow[t]{3}{*}{$\Gamma$} & & $0.361^{* *}$ & & & \\
\hline & $R_{3 t}$ & $0.757^{* * *}$ & 0.110 & & \\
\hline & $R_{4 t}$ & 0.048 & $0.810^{* * *}$ & 0.208 & \\
\hline \multirow{2}{*}{$\begin{array}{l}\theta_{1} \\
\theta_{2}\end{array}$} & & \multirow{2}{*}{\multicolumn{4}{|c|}{$\begin{array}{l}0.975^{* * *} \\
0.022^{* * *}\end{array}$}} \\
\hline & & & & & \\
\hline
\end{tabular}

Panel B: Country $i$ 's Bond Returns $\left(R_{i 5 t}\right)$

\begin{tabular}{|c|c|c|c|c|c|c|c|c|c|}
\hline & $\mathrm{Be}$ & $\mathrm{De}$ & $\mathrm{Fr}$ & $\mathrm{Ge}$ & It & $\mathrm{Ne}$ & $\mathrm{Sp}$ & Sw & UK \\
\hline$c_{0}$ & $-1.274^{* * *}$ & $-1.202^{* * *}$ & $-1.456^{* * *}$ & $-1.298^{* * *}$ & $-1.575^{* * *}$ & $-1.367^{* * *}$ & $-1.630^{* * *}$ & $-1.902^{* * *}$ & $-1.693^{* * *}$ \\
\hline$c_{1}$ & $0.081 * * *$ & $0.058 * * *$ & $0.083^{* * *}$ & $0.088^{* * *}$ & $0.079 * * *$ & $0.092 * * *$ & $0.084^{* * *}$ & 0.034 & $0.109 * * *$ \\
\hline$c_{2}$ & $-0.013^{* * *}$ & $-0.011^{*}$ & $-0.014^{* * *}$ & $-0.012 * * *$ & $-0.016^{* * *}$ & $-0.016^{* * *}$ & $-0.014^{* * *}$ & $-0.013^{*}$ & $-0.021^{* *}$ \\
\hline$c_{3}$ & 0.042 & $0.122^{* *}$ & 0.023 & -0.052 & -0.037 & -0.015 & 0.027 & $0.149 * *$ & -0.080 \\
\hline$c_{4}$ & $0.012^{* * *}$ & $0.013^{* * *}$ & $0.011^{* * *}$ & $0.011^{* * *}$ & $0.018^{* * *}$ & $0.015^{* * *}$ & $0.013^{* * *}$ & $0.017^{* *}$ & $0.018^{* *}$ \\
\hline$c_{5}$ & -0.047 & $-0.104^{*}$ & -0.021 & 0.045 & 0.066 & 0.010 & -0.039 & $-0.089^{*}$ & 0.034 \\
\hline$c_{6}\left(z_{t-1}\right)$ & $-0.003^{* * *}$ & $-0.003^{* * *}$ & $-0.004^{* * *}$ & $-0.003^{* * *}$ & $-0.004^{* * *}$ & $-0.004^{* * *}$ & $-0.004 * * *$ & $-0.005^{* * *}$ & $-0.005 * * *$ \\
\hline$\gamma_{01}$ & $0.361^{* * *}$ & $0.410^{* * *}$ & $0.474^{* * *}$ & $0.381^{* * *}$ & $0.227^{* * *}$ & $0.417^{* * *}$ & $0.329^{* * *}$ & $0.455^{* * *}$ & $0.599^{* *}$ \\
\hline$\gamma_{11}$ & $0.116^{* * *}$ & -0.010 & -0.008 & $0.083^{* *}$ & $0.233^{* * *}$ & 0.042 & $0.143^{* *}$ & -0.009 & 0.013 \\
\hline$\gamma_{02}$ & $0.103^{* * *}$ & $0.152^{* * *}$ & $0.140 * * *$ & $0.103^{* * *}$ & $0.089 * * *$ & $0.110^{* * *}$ & $0.063^{* * *}$ & $0.126 * * *$ & $0.202^{* * *}$ \\
\hline$\gamma_{12}$ & $-0.111^{* * *} *$ & $-0.169 * * *$ & $-0.146 * * *$ & $-0.112 * * *$ & $-0.089 * * *$ & $-0.116^{* * *}$ & $-0.068 * * *$ & $-0.140 * * *$ & $-0.217 * * *$ \\
\hline$\gamma_{03}$ & $0.657^{* * *}$ & $0.855^{* * *}$ & $0.834^{* * *}$ & $0.673^{* * *}$ & $0.604^{* * *}$ & $0.747^{* * *}$ & $0.591 * * *$ & $0.829 * * *$ & $1.101^{* * *}$ \\
\hline$\gamma_{13}$ & $0.272^{* * *}$ & -0.102 & $0.109^{*}$ & $0.253^{* * *}$ & $0.308^{* * *}$ & $0.188^{* * *}$ & $0.339 * * *$ & -0.029 & 0.068 \\
\hline$\gamma_{04}$ & $-0.000 * * *$ & $-0.000^{* * *}$ & $-0.000 * * *$ & $-0.000 * * *$ & -0.000 & $-0.012^{* * *}$ & $-0.015^{* * *}$ & $-0.008^{* * *}$ & -0.006 \\
\hline$\gamma_{14}$ & -0.003 & 0.004 & -0.003 & 0.001 & 0.004 & -0.002 & -0.001 & 0.004 & 0.008 \\
\hline$\omega$ & $4 \cdot 10^{-8}$ & $6 \cdot 10^{-8}$ & $4 \cdot 10^{-8}$ & $5 \cdot 10^{-8 *}$ & $3 \cdot 10^{-8}$ & $2 \cdot 10^{-8}$ & $3 \cdot 10^{-8 *}$ & $6 \cdot 10^{-8}$ & $3 \cdot 10^{-8}$ \\
\hline$\alpha$ & 0.107 & $0.126^{* * *}$ & $0.118^{*}$ & $0.103^{* * *}$ & $0.116^{* * *}$ & $0.102^{* * *}$ & $0.106^{* * *}$ & $0.065^{*}$ & $0.082^{* *}$ \\
\hline$\beta$ & $0.890^{* * *}$ & $0.873^{* * *}$ & $0.879^{* * *}$ & $0.673^{* * *}$ & $0.880^{* * *}$ & $0.895^{* * *}$ & $0.893^{* * *}$ & $0.933^{* * *}$ & $0.906^{* * *}$ \\
\hline
\end{tabular}

Panel C: Country $i$ 's Stock Returns $\left(R_{i 6 t}\right)$

\begin{tabular}{|c|c|c|c|c|c|c|c|c|c|}
\hline & $\mathrm{Be}$ & $\mathrm{De}$ & Fr & $\mathrm{Ge}$ & It & $\mathrm{Ne}$ & $\mathrm{Sp}$ & $\mathrm{Sw}$ & UK \\
\hline$d_{0}$ & $-0.985^{* * *}$ & $-0.899^{* * *}$ & $-1.070^{* * *}$ & $-0.404^{* *}$ & $-1.784^{* * *}$ & $-1.959^{* * *}$ & $-2.415^{* * *}$ & $-4.239^{* * *}$ & $-2.918^{* * *}$ \\
\hline$d_{1}$ & -0.002 & 0.228 & -0.033 & 0.072 & -0.188 & 0.043 & 0.083 & -0.041 & 0.113 \\
\hline$d_{2}$ & -0.042 & -0.054 & -0.005 & 0.030 & -0.060 & 0.029 & 0.067 & -0.056 & 0.021 \\
\hline$d_{3}$ & 0.152 & -0.167 & 0.072 & -0.081 & -0.436 & $0.151^{*}$ & 0.048 & 0.215 & 0.083 \\
\hline$d_{4}$ & $0.102 * *$ & $0.169 * * *$ & -0.015 & 0.084 & -0.102 & $0.119^{* *}$ & 0.048 & 0.086 & -0.012 \\
\hline$d_{5}$ & 0.133 & 0.050 & 0.215 & 0.016 & 0.396 & 0.012 & $0.288^{*}$ & -0.178 & 0.119 \\
\hline$d_{6}$ & -0.003 & -0.022 & -0.045 & -0.087 & $0.148^{* * *}$ & $-0.117^{* *}$ & $-0.079^{*}$ & $-0.070^{*}$ & -0.032 \\
\hline$d_{7}\left(z_{t-1}\right)$ & $-0.003^{* * *}$ & $-0.002^{* * *}$ & $-0.003^{* * *}$ & $-0.001^{* *}$ & $0.005^{* * *}$ & $-0.005^{* * *}$ & $-0.006^{* * *}$ & $-0.011 * * *$ & $-0.008^{* * *}$ \\
\hline$\delta_{01}$ & $0.578^{* * *}$ & $0.820^{* * *}$ & $0832^{* * *}$ & $0.598^{* * *}$ & $0.926^{* * *}$ & $0.521^{* * *}$ & $0.675^{* * *}$ & $0.693^{* * *}$ & $0.536^{* * *}$ \\
\hline$\delta_{11}$ & $-1.003^{* * *}$ & $-1.483^{* * *}$ & $-1.580 * * *$ & $-1.505^{* * *}$ & $-1.864^{* * *}$ & $-1.317 * * *$ & $-1.569 * * *$ & $-1.828^{* * *}$ & $-1.020 * * *$ \\
\hline$\delta_{02}$ & $0.577^{* * *}$ & $0.518^{* * *}$ & $0.943^{* * *}$ & $0.824^{* * *}$ & $0.724^{* * *}$ & $0.704^{* * *}$ & $0.814^{* * *}$ & $1.023^{* * *}$ & $0.742^{* * *}$ \\
\hline$\delta_{12}$ & $-0.135^{*}$ & -0.035 & -0.227 & -0.010 & -0.080 & $-0.118^{*}$ & $-0.195^{* *}$ & -0.012 & $-0.235 * * *$ \\
\hline$\delta_{03}$ & $0.890 * * *$ & $1.139 * * *$ & $1.732^{* * *}$ & $1.341^{* * *}$ & $1.597 * * *$ & $0.889 * * *$ & 1.439 & $1.280 * * *$ & $1.175^{* * *}$ \\
\hline$\delta_{13}$ & -0.565 & $-1.582^{* * *}$ & $-3.240 * * *$ & $-2.491^{* * *}$ & $-4.325^{* * *}$ & $-1.838^{* * *}$ & $-3.159 * * *$ & $-3.230 * * *$ & $-1.856 * * *$ \\
\hline$\delta_{04}$ & $2 \cdot 10^{-4 * * *}$ & $5 \cdot 10^{-5}$ & $-2 \cdot 10^{-4 * *}$ & $-5 \cdot 10^{-5}$ & $9 \cdot 10^{-4}$ & $-3 \cdot 10^{-4}$ & $-1 \cdot 10^{-4}$ & $-1 \cdot 10^{-4}$ & $0.003 * * *$ \\
\hline$\delta_{14}$ & $0.272^{* *}$ & $0.299^{* * *}$ & $0.570 * * *$ & $0.595^{* * *}$ & $0.591^{* * *}$ & $0.606^{* * *}$ & $0.498^{* * *}$ & $0.609 * * *$ & $0.462^{* * *}$ \\
\hline$\delta_{05}$ & $0.003^{* * *}$ & $0.004^{* * *}$ & $0.004^{* * *}$ & $0.003^{* * *}$ & $0.008^{* * *}$ & $0.001^{*}$ & $0.006^{* * *}$ & $0.006^{* * *}$ & $0.004^{* * *}$ \\
\hline$\delta_{15}$ & $-0.004^{* *}$ & $-0.004^{* *}$ & $-0.007^{* * *}$ & $-0.006^{* * *}$ & $-0.011^{* * *}$ & $-0.004^{* * *}$ & $-0.008^{* * *}$ & $-0.007 * * *$ & $-0.006^{* * *}$ \\
\hline$\omega$ & $4 \cdot 10^{-5 * *}$ & $1 \cdot 10^{-5}$ & $4 \cdot 10^{-5 * *}$ & $4 \cdot 10^{-5 * *}$ & $3 \cdot 10^{-7 * * *}$ & $1 \cdot 10^{-5 * * *}$ & $9 \cdot 10^{-6 *}$ & $2 \cdot 10^{-5 *}$ & $9 \cdot 10^{-6 * *}$ \\
\hline$\alpha$ & $0.280 * * *$ & $0.058 * *$ & $0.220 * * *$ & $0.191 * * *$ & $0.025^{* * *}$ & $0.185^{* * *}$ & $0.060 * * *$ & $0.085^{* *}$ & $0.104^{* * *}$ \\
\hline$\beta$ & $0.614^{* * *}$ & $0.911^{* * *}$ & $0.649^{* * *}$ & $0.676^{* * *}$ & $0.975^{* * *}$ & $0.759^{* * *}$ & $0.915^{* * *}$ & $0.883^{* * *}$ & $0.856^{* * *}$ \\
\hline
\end{tabular}

The table reports the results from estimating the volatility-spillover model presented in the text. $R_{1 t}, R_{2 t}$, $R_{3 t}, R_{4 t}, R_{i 5 t}$, and $R_{i 6 t}$ are the US bond return, LSSstock return, European bond return, the European stock return, country $i$ bond return, and country $i$ stock return, respectively. Based on Bollerslev and Wooldridge (1992) robust standard errors, $* / * * / * *$ indicates that the parameter is significant at the $10 \% / 5 \% / 1 \%$ level of significance.

Table 2: Volatility-Spillover Model 


\begin{tabular}{|c|c|c|c|c|}
\hline & \multicolumn{2}{|c|}{ - Idio Shocks-- } & \multicolumn{2}{|c|}{${ }_{-}-$Unexp Returns ${ }_{-}$} \\
\hline & $\begin{array}{c}\bar{\sigma}_{1} / \bar{\sigma}_{3} \\
\text { Bonds }\end{array}$ & $\begin{array}{c}\bar{\sigma}_{2} / \bar{\sigma}_{4} \\
\text { Stocks }\end{array}$ & $\begin{array}{c}\sqrt{h_{1}} / \sqrt{h_{3}} \\
\text { Bonds }\end{array}$ & $\begin{array}{c}\sqrt{h_{2}} / \sqrt{h_{4}} \\
\text { Stocks }\end{array}$ \\
\hline US & 0.603 & 1.927 & 0.603 & 2.073 \\
\hline $\mathrm{Eu}$ & 0.454 & 11.097 & 0.470 & 1.999 \\
\hline & \multicolumn{2}{|c|}{ - Residuals - } & \multicolumn{2}{|c|}{ - Unexp Returns - } \\
\hline & $\begin{array}{c}\bar{\sigma}_{i 5} \\
\text { Bonds }\end{array}$ & $\begin{array}{c}\bar{\sigma}_{i 6} \\
\text { Stocks }\end{array}$ & $\begin{array}{l}\sqrt{h_{i 5}} \\
\text { Bonds }\end{array}$ & $\begin{array}{c}\sqrt{h_{i 6}} \\
\text { Stocks }\end{array}$ \\
\hline $\mathrm{Be}$ & 0.251 & 1.762 & 0.536 & 3.071 \\
\hline De & 0.318 & 1.897 & 0.607 & 3.316 \\
\hline $\mathrm{Fr}$ & 0.264 & 1.744 & 0.602 & 4.672 \\
\hline $\mathrm{Ge}$ & 0.229 & 1.702 & 0.517 & 4.682 \\
\hline It & 0.380 & 2.633 & 0.599 & 5.365 \\
\hline $\mathrm{Ne}$ & 0.229 & 1.498 & 0.542 & 4.330 \\
\hline Sp & 0.366 & 1.892 & 0.588 & 4.376 \\
\hline $\mathrm{Sw}$ & 0.489 & 2.346 & 0.718 & 5.464 \\
\hline UK & 0.487 & 1.392 & 0.864 & 3.673 \\
\hline
\end{tabular}

The top part of the table reports the average conditional standard deviations (multiplied by 100) of the idiosyncratic shocks $\left(e_{j} \mathrm{~s}\right)$ and the unexpected returns $\left(\epsilon_{j} \mathrm{~s}\right)$ from the first and second steps of the volatilityspillover model presented in the text for which the parameter estimates are given in Table 2. The bottom part of the table reports the average conditional standard deviations (multiplied by 100) of the residuals $\left(e_{i j} \mathrm{~s}\right)$ and the unexpected returns $\left(\epsilon_{i j} \mathrm{~s}\right)$ from the third and fourth steps of the volatility-spillover model.

Table 3: Average Conditional Volatilities 


\begin{tabular}{|c|c|c|c|c|c|c|}
\hline \multicolumn{7}{|c|}{$\begin{array}{l}\text { - Bonds - } \\
\text { Pre euro }\end{array}$} \\
\hline & $\overline{V R} R_{1}$ & $\bar{V} R_{2}$ & $\bar{V} R_{3}$ & $\bar{V} R_{4}$ & $\bar{V} R_{5}$ & \\
\hline & US-bond & US-stock & Eu-bond & Eu-stock & Own-bond & \\
\hline $\mathrm{Be}$ & 0.166 & 0.124 & 0.392 & 0.0006 & 0.317 & \\
\hline De & 0.130 & 0.156 & 0.407 & 0.0001 & 0.307 & \\
\hline Fr & 0.189 & 0.146 & 0.419 & 0.0004 & 0.245 & \\
\hline $\mathrm{Ge}$ & 0.189 & 0.124 & 0.418 & 0.0003 & 0.269 & \\
\hline It & 0.059 & 0.090 & 0.281 & 0.0004 & 0.569 & \\
\hline $\mathrm{Ne}$ & 0.195 & 0.122 & 0.443 & 0.0005 & 0.239 & \\
\hline $\mathrm{Sp}$ & 0.126 & 0.047 & 0.273 & 0.0006 & 0.554 & \\
\hline $\mathrm{Sw}$ & 0.120 & 0.088 & 0.279 & 0.0001 & 0.512 & \\
\hline UK & 0.148 & 0.148 & 0.364 & 0.00006 & 0.341 & \\
\hline \multicolumn{7}{|c|}{ Post euro } \\
\hline & $\overline{V R_{1}}$ & $\bar{V} R_{2}$ & $\bar{V} R_{3}$ & $\bar{V} R_{4}$ & $\bar{V} R_{5}$ & \\
\hline & US-bond & US-stock & Eu-bond & Eu-stock & Own-bond & \\
\hline $\mathrm{Be}$ & 0.432 & 0.001 & 0.471 & 0.0002 & 0.095 & \\
\hline De & 0.399 & 0.011 & 0.402 & 0.0005 & 0.188 & \\
\hline $\mathrm{Fr}$ & 0.416 & 0.001 & 0.487 & 0.0002 & 0.096 & \\
\hline $\mathrm{Ge}$ & 0.426 & 0.002 & 0.487 & 0.000008 & 0.085 & \\
\hline It & 0.425 & 0.000005 & 0.480 & 0.0003 & 0.095 & \\
\hline $\mathrm{Ne}$ & 0.415 & 0.001 & 0.495 & 0.0001 & 0.089 & \\
\hline $\mathrm{Sp}$ & 0.430 & 0.001 & 0.478 & 0.00005 & 0.090 & \\
\hline $\mathrm{Sw}$ & 0.363 & 0.005 & 0.331 & 0.0003 & 0.300 & \\
\hline UK & 0.342 & 0.003 & 0.352 & 0.0006 & 0.302 & \\
\hline \multicolumn{7}{|c|}{$\begin{array}{c}\text { - Stocks - } \\
\text { Pre euro }\end{array}$} \\
\hline & $V \bar{R}^{*}{ }_{1}$ & $V \bar{R}_{2}^{*}$ & $V \bar{R}^{*}{ }_{3}$ & $V \bar{R}_{4}^{*}$ & $V \bar{R}^{*}{ }_{5}$ & $V \bar{R}^{*}{ }_{6}$ \\
\hline & US-bond & US-stock & Eu-bond & Eu-stock & Own-bond & Own-stock \\
\hline $\mathrm{Be}$ & 0.032 & 0.257 & 0.061 & 0.0002 & 0.0000002 & 0.649 \\
\hline De & 0.050 & 0.170 & 0.077 & 0.000007 & 0.0000005 & 0.703 \\
\hline $\mathrm{Fr}$ & 0.037 & 0.383 & 0.126 & 0.00007 & 0.0000002 & 0.453 \\
\hline $\mathrm{Ge}$ & 0.024 & 0.365 & 0.095 & 0.000006 & 0.0000001 & 0.516 \\
\hline It & 0.030 & 0.156 & 0.068 & 0.0009 & 0.000002 & 0.745 \\
\hline $\mathrm{Ne}$ & 0.028 & 0.397 & 0.064 & 0.0003 & 0.00000002 & 0.510 \\
\hline Sp & 0.045 & 0.300 & 0.113 & 0.0001 & 0.000002 & 0.542 \\
\hline Sw & 0.020 & 0.346 & 0.052 & 0.00002 & 0.000002 & 0.583 \\
\hline UK & 0.028 & 0.411 & 0.093 & 0.0002 & 0.000002 & 0.468 \\
\hline \multicolumn{7}{|c|}{ Post euro } \\
\hline & $V \bar{R}^{*} 1$ & $V \bar{R}_{2}^{*}$ & $V \bar{R}^{*}{ }_{3}$ & $V \bar{R}_{4}^{*}$ & $V \bar{R}^{*}{ }_{5}$ & $V \bar{R}^{*} 6$ \\
\hline & US-bond & US-stock & Eu-bond & Eu-stock & Own-bond & Own-stock \\
\hline $\mathrm{Be}$ & 0.018 & 0.231 & 0.003 & 0.055 & 0.00000001 & 0.693 \\
\hline $\mathrm{De}$ & 0.032 & 0.223 & 0.004 & 0.059 & 0.00000001 & 0.682 \\
\hline $\mathrm{Fr}$ & 0.034 & 0.385 & 0.041 & 0.160 & 0.00000004 & 0.380 \\
\hline $\mathrm{Ge}$ & 0.043 & 0.430 & 0.021 & 0.153 & 0.00000003 & 0.353 \\
\hline It & 0.039 & 0.240 & 0.094 & 0.146 & 0.00000002 & 0.480 \\
\hline $\mathrm{Ne}$ & 0.047 & 0.319 & 0.019 & 0.204 & 0.00000003 & 0.411 \\
\hline $\mathrm{Sp}$ & 0.048 & 0.290 & 0.056 & 0.127 & 0.00000001 & 0.450 \\
\hline $\mathrm{Sw}$ & 0.040 & 0.398 & 0.039 & 0.103 & 0.00000001 & 0.420 \\
\hline UK & 0.024 & 0.338 & 0.014 & 0.169 & 0.0000001 & 0.456 \\
\hline
\end{tabular}

The table reports the average variance ratios based on the volatility-spillover model presented in the text for which the parameter estimates are given in Table 2.

Table 4: Variance Ratios 


\begin{tabular}{|c|c|c|c|c|c|c|}
\hline \multicolumn{7}{|c|}{$\begin{array}{c}\text { - Bonds - } \\
\text { Pre euro }\end{array}$} \\
\hline & $\bar{V} R_{1}$ & $\overline{V R} R_{2}$ & $\overline{V R_{3}}$ & $\bar{V} R_{4}$ & $\overline{V R} R_{5}$ & \\
\hline & Eu-bond & Eu-stock & US-bond & US-stock & Own-bond & \\
\hline $\mathrm{Be}$ & 0.658 & 0.0009 & 0.0005 & 0.014 & 0.326 & \\
\hline De & 0.666 & 0.00005 & 0.00001 & 0.0005 & 0.333 & \\
\hline $\mathrm{Fr}$ & 0.754 & 0.0002 & 0.003 & 0.003 & 0.240 & \\
\hline $\mathrm{Ge}$ & 0.742 & 0.000007 & 0.003 & 0.0008 & 0.253 & \\
\hline It & 0.484 & 0.0007 & 0.047 & 0.003 & 0.465 & \\
\hline $\mathrm{Ne}$ & 0.767 & 0.0001 & 0.003 & 0.0004 & 0.229 & \\
\hline $\mathrm{Sp}$ & 0.363 & 0.00005 & 0.016 & 0.040 & 0.581 & \\
\hline $\mathrm{Sw}$ & 0.476 & 0.001 & 0.0006 & 0.0006 & 0.521 & \\
\hline UK & 0.621 & 0.0001 & 0.0001 & 0.000007 & 0.378 & \\
\hline \multicolumn{7}{|c|}{ Post euro } \\
\hline & $\bar{V} R_{1}$ & $\overline{V R} R_{2}$ & $\bar{V} R_{3}$ & $\bar{V} R_{4}$ & $\overline{V R_{5}}$ & \\
\hline & Eu-bond & Eu-stock & US-bond & US-stock & Own-bond & \\
\hline $\mathrm{Be}$ & 0.974 & 0.0000051 & 0.0001 & 0.00002 & 0.026 & \\
\hline $\mathrm{De}$ & 0.883 & 0.0000004 & 0.00000002 & 0.00004 & 0.117 & \\
\hline $\mathrm{Fr}$ & 0.979 & 0.00002 & 0.000007 & 0.00001 & 0.021 & \\
\hline $\mathrm{Ge}$ & 0.981 & 0.00005 & 0.000002 & 0.00001 & 0.019 & \\
\hline It & 0.966 & 0.0002 & 0.00009 & 0.000006 & 0.033 & \\
\hline $\mathrm{Ne}$ & 0.980 & 0.00002 & 0.00001 & 0.00000005 & 0.020 & \\
\hline $\mathrm{Sp}$ & 0.973 & 0.00002 & 0.00005 & 0.00002 & 0.027 & \\
\hline $\mathrm{Sw}$ & 0.721 & 0.001 & 0.001 & 0.0004 & 0.276 & \\
\hline UK & 0.743 & 0.000073 & 0.00000093 & 0.000005 & 0.257 & \\
\hline \multicolumn{7}{|c|}{$\begin{array}{c}\text { - Stocks - } \\
\text { Pre euro }\end{array}$} \\
\hline & $V \bar{R}^{*}{ }_{1}$ & $V \bar{R}^{*} 2$ & $V \bar{R}^{*}{ }_{3}$ & $V \bar{R}_{4}^{*}$ & $V \bar{R}^{*}{ }_{5}$ & $V \bar{R}^{*}{ }_{6}$ \\
\hline & Eu-bond & Eu-stock & US-bond & US-stock & Own-bond & Own-stock \\
\hline $\mathrm{Be}$ & 0.101 & 0.345 & 0.001 & 0.005 & 0.0000002 & 0.520 \\
\hline $\mathrm{De}$ & 0.109 & 0.249 & 0.009 & 0.0005 & 0.0000004 & 0.632 \\
\hline $\mathrm{Fr}$ & 0.191 & 0.485 & 0.0002 & 0.0009 & 0.0000002 & 0.323 \\
\hline $\mathrm{Ge}$ & 0.140 & 0.489 & 0.00002 & 0.001 & 0.0000001 & 0.370 \\
\hline It & 0.105 & 0.238 & 0.0007 & 0.0004 & 0.000001 & 0.656 \\
\hline $\mathrm{Ne}$ & 0.110 & 0.563 & 0.0002 & 0.001 & 0.00000001 & 0.326 \\
\hline $\mathrm{Sp}$ & 0.143 & 0.373 & 0.0004 & 0.001 & 0.000002 & 0.474 \\
\hline $\mathrm{Sw}$ & 0.075 & 0.413 & 0.0001 & 0.0005 & 0.000001 & 0.510 \\
\hline UK & 0.152 & 0.539 & 0.001 & 0.002 & 0.000008 & 0.306 \\
\hline \multicolumn{7}{|c|}{$\begin{array}{c}\text { - Stocks - } \\
\text { Post euro }\end{array}$} \\
\hline & $V \bar{R}^{*}{ }_{1}$ & $V \bar{R}^{*} 2$ & $V \bar{R}^{*}{ }_{3}$ & $V \bar{R}_{4}^{*}$ & $V \bar{R}^{*}{ }_{5}$ & $V \bar{R}^{*}{ }_{6}$ \\
\hline & Eu-bond & Eu-stock & US-bond & US-stock & Own-bond & Own-stock \\
\hline $\mathrm{Be}$ & 0.009 & 0.350 & 0.010 & 0.0007 & 0.000 & 0.630 \\
\hline De & 0.021 & 0.335 & 0.008 & 0.0008 & 0.000 & 0.635 \\
\hline Fr & 0.037 & 0.738 & 0.000007 & 0.0001 & 0.000 & 0.226 \\
\hline $\mathrm{Ge}$ & 0.023 & 0.713 & 0.004 & 0.005 & 0.000 & 0.256 \\
\hline It & 0.064 & 0.591 & 0.0003 & 0.0008 & 0.000 & 0.344 \\
\hline $\mathrm{Ne}$ & 0.038 & 0.654 & 0.002 & 0.000006 & 0.000 & 0.306 \\
\hline $\mathrm{Sp}$ & 0.054 & 0.562 & 0.000003 & 0.001 & 0.000 & 0.383 \\
\hline $\mathrm{Sw}$ & 0.056 & 0.544 & 0.0000062 & 0.00001 & 0.000 & 0.400 \\
\hline UK & 0.021 & 0.676 & 0.003 & 0.0004 & 0.000 & 0.299 \\
\hline
\end{tabular}

The table reports the average variance ratios based on the volatility-spillover model presented in the text with the following modification: The influence goes from Europe to the US, i.e. now $R_{1 t}, R_{2 t}, R_{3 t}$, and $R_{4 t}$ refer to the European bond return, the European stock return, the US bond return, and the US stock return, respectively. Invariably, $R_{i 5 t}$ and $R_{i 6 t}$ are country $i$ bond return and country $i$ stock return.

Table 5: Variance Ratios $(\mathrm{Eu} \rightarrow \mathrm{US} \rightarrow$ Country- $i)$ 


\begin{tabular}{|c|c|c|c|c|c|c|}
\hline \multicolumn{7}{|c|}{$\begin{array}{c}\text { - Stocks - } \\
\text { Pre euro }\end{array}$} \\
\hline & $\overline{V R_{1}}$ & $\bar{V} R_{2}$ & $\bar{V} R_{3}$ & $\bar{V} R_{4}$ & $\overline{V R} R_{5}$ & \\
\hline & US-stock & US-bond & Eu-stock & EU-bond & Own-stock & \\
\hline $\mathrm{Be}$ & 0.173 & 0.036 & 0.244 & 0.000003 & 0.547 & \\
\hline $\mathrm{De}$ & 0.107 & 0.074 & 0.219 & 0.002 & 0.598 & \\
\hline Fr & 0.216 & 0.057 & 0.409 & 0.0005 & 0.317 & \\
\hline $\mathrm{Ge}$ & 0.247 & 0.026 & 0.369 & 0.0007 & 0.358 & \\
\hline It & 0.132 & 0.020 & 0.291 & 0.0006 & 0.556 & \\
\hline $\mathrm{Ne}$ & 0.292 & 0.027 & 0.352 & 0.002 & 0.327 & \\
\hline $\mathrm{Sp}$ & 0.206 & 0.031 & 0.273 & 0.0002 & 0.490 & \\
\hline $\mathrm{Sw}$ & 0.230 & 0.010 & 0.241 & 0.005 & 0.515 & \\
\hline UK & 0.252 & 0.042 & 0.429 & 0.00006 & 0.278 & \\
\hline \multicolumn{7}{|c|}{$\begin{array}{c}\text { - Stocks - } \\
\text { Post euro }\end{array}$} \\
\hline & $\bar{V} R_{1}$ & $\bar{V} R_{2}$ & $\bar{V} R_{3}$ & $V R_{4}$ & $\overline{V R_{5}}$ & \\
\hline & US-stock & US-bond & Eu-stock & EU-bond & Own-stock & \\
\hline $\mathrm{Be}$ & 0.267 & 0.012 & 0.104 & 0.034 & 0.582 & \\
\hline De & 0.243 & 0.025 & 0.129 & 0.004 & 0.598 & \\
\hline Fr & 0.431 & 0.024 & 0.340 & 0.00007 & 0.206 & \\
\hline $\mathrm{Ge}$ & 0.487 & 0.032 & 0.265 & 0.00002 & 0.216 & \\
\hline It & 0.350 & 0.025 & 0.271 & 0.0007 & 0.353 & \\
\hline $\mathrm{Ne}$ & 0.391 & 0.030 & 0.291 & 0.003 & 0.285 & \\
\hline Sp & 0.361 & 0.032 & 0.238 & 0.005 & 0.368 & \\
\hline $\mathrm{Sw}$ & 0.450 & 0.027 & 0.182 & 0.002 & 0.339 & \\
\hline UK & 0.432 & 0.025 & 0.257 & 0.0003 & 0.287 & \\
\hline \multicolumn{7}{|c|}{$\begin{array}{l}\text { - Bonds - } \\
\text { Pre euro }\end{array}$} \\
\hline & $V \bar{R}^{*}{ }_{1}$ & $V \bar{R}_{2}^{*}$ & $V \bar{R}_{3}^{*}$ & $V \bar{R}_{4}^{*}$ & $V \bar{R}^{*}{ }_{5}$ & $V \bar{R}^{*}{ }_{6}$ \\
\hline & US-stock & US-bond & EU-stock & EU-bond & Own-stock & Own-bond \\
\hline $\mathrm{Be}$ & 0.054 & 0.210 & 0.083 & 0.00005 & 0.000004 & 0.653 \\
\hline De & 0.056 & 0.207 & 0.113 & 0.0001 & 0.00001 & 0.623 \\
\hline Fr & 0.086 & 0.272 & 0.094 & 0.0002 & 0.00001 & 0.548 \\
\hline $\mathrm{Ge}$ & 0.044 & 0.267 & 0.097 & 0.0004 & 0.000006 & 0.591 \\
\hline It & 0.022 & 0.040 & 0.069 & 0.00002 & 0.00002 & 0.869 \\
\hline $\mathrm{Ne}$ & 0.047 & 0.263 & 0.107 & 0.0001 & 0.0000001 & 0.582 \\
\hline $\mathrm{Sp}$ & 0.008 & 0.049 & 0.024 & 0.0002 & 0.00001 & 0.919 \\
\hline Sw & 0.030 & 0.172 & 0.042 & 0.002 & 0.00002 & 0.755 \\
\hline UK & 0.051 & 0.247 & 0.159 & 0.0001 & 0.000007 & 0.542 \\
\hline \multicolumn{7}{|c|}{$\begin{array}{l}\text { - Bonds - } \\
\text { Post euro }\end{array}$} \\
\hline & $V \bar{R}^{*}{ }_{1}$ & $V \bar{R}_{2}^{*}$ & $V \bar{R}_{3}^{*}$ & $V \bar{R}_{4}^{*}$ & $V \bar{R}^{*} 5$ & $V \bar{R}^{*}{ }_{6}$ \\
\hline & US-stock & US-bond & EU-stock & EU-bond & Own-stock & Own-bond \\
\hline $\mathrm{Be}$ & 0.003 & 0.395 & 0.016 & 0.381 & 0.000001 & 0.205 \\
\hline $\mathrm{De}$ & 0.014 & 0.341 & 0.019 & 0.331 & 0.0000002 & 0.294 \\
\hline $\mathrm{Fr}$ & 0.005 & 0.368 & 0.016 & 0.411 & 0.0099991 & 0.202 \\
\hline $\mathrm{Ge}$ & 0.003 & 0.374 & 0.009 & 0.405 & 0.00000005 & 0.210 \\
\hline It & 0.0003 & 0.356 & 0.006 & 0.406 & 0.00000008 & 0.231 \\
\hline $\mathrm{Ne}$ & 0.004 & 0.385 & 0.016 & 0.399 & 0.000002 & 0.196 \\
\hline $\mathrm{Sp}$ & 0.0007 & 0.366 & 0.012 & 0.387 & 0.00000006 & 0.234 \\
\hline $\mathrm{Sw}$ & 0.013 & 0.319 & 0.019 & 0.231 & 0.00000007 & 0.418 \\
\hline UK & 0.012 & 0.249 & 0.011 & 0.263 & 0.000003 & 0.419 \\
\hline
\end{tabular}

The table reports the average variance ratios based on the volatility-spillover model presented in the text with the following modification: The influence goes from stock markets to bond markets, i.e. now $R_{1 t}$, $R_{2 t}, R_{3 t}, R_{4 t}, R_{i 5 t}$, and $R_{i 6 t}$ refer to the US stock return, the US bond return, the European stock return, the European bond return, country $i$ stock return, and country $i$ bond return, respectively.

Table 6: Variance Ratios (Stocks $\rightarrow$ Bonds) 


\section{Working Papers from Finance Research Group}

F-2004-01 Charlotte Christiansen: Decomposing European bond and equity volatility. 
ISBN 87-7882-000-6

Department of Accounting, Finance and Logistics

Faculty of Business Administration

Aarhus School of Business

Fuglesangs Allé 4

DK-8210 Aarhus V - Denmark

Tel. +4589486688

Fax +4586150188

www.asb.dk 